\title{
Physical Modelling of Tsunami Onshore Propagation, Peak Pressures, and Shielding Effects in an Urban Building Array
}

\author{
Tori Tomiczek ${ }^{\mathrm{a}}$ (corresponding author), Adi Prasetyo ${ }^{\mathrm{b}}$, Nobuhito Mori ${ }^{\mathrm{b}}$, \\ Tomohiro Yasuda ${ }^{\mathrm{c}}$, Andrew Kennedy ${ }^{\mathrm{a}}$ \\ a University of Notre Dame, 156 Fitzpatrick Hall, Notre Dame, IN 46556, USA, \\ vtomicze@nd.edu, Andrew.B.Kennedy.117@nd.edu \\ b. Kyoto University, Disaster Prevention Research Institute, Gokasho, Uji, Kyoto, 6110011, Japan, \\ adi.prasetyo246@yahoo.com,mori@oceanwave.ac.jp, \\ c. Kansai University, 3-3-35 Yamate-cho, Suita, Osaka, 5648680, Japan, tomo@oceanwave.jp
}

\begin{abstract}
Wave experiments were conducted on a 1:20 length scale to measure water surface elevations and extreme pressures on and around idealized structural elements and arrays of structures. Experiments varied offshore wave characteristics and onshore structural configurations. Conditions in which waves broke on or just before the specimen caused maximum impulsive pressures. Pressures measured under nonbreaking wave conditions agreed with predicted values using design equations suggested by the Japanese Cabinet Office; however bare-earth water surface elevation inputs produced nonconservative estimates in breaking wave trials. Shielded structures experienced pressure reductions of 40-70\% under breaking wave conditions. Results indicate that shielding elements constructed nearshore may reduce wave-induced damage. This dataset may be used to validate numerical models of tsunami propagation through urban environments.
\end{abstract}

\section{Keywords}

Tsunami Experiments, Inundation, Macro-Roughness, Pressure, Setback 


\section{Introduction}

\subsection{Coastal Hazards}

Coastal environments offer valuable sources of economy, transportation, and recreation, spurring a high concentration of people to settle near the coastline. The population density of coastal regions $100 \mathrm{~km}$ or closer to shore and within $100 \mathrm{~m}$ of sea level is over 2.5 times that of the global average, with the majority living in small coastal villages with $<1000$ people $/ \mathrm{km}^{2}$ (Nicholls and Small, 2002, Small and Nicholls, 2003). However, these communities are vulnerable to coastal hazards including tsunamis and hurricanes. In recent years, the 2004 Indian Ocean Tsunami (e.g. Papadopoulos et al., 2006, Tsuji et al., 2006, Koshimura et al., 2009, Leone et al., 2011) and the 2011 Tohoku Earthquake Tsunami in Japan (e.g. Mimura et al., 2011, Mori et al., 2011, Mori et al., 2012, Kazama and Noda, 2012, Udo et al., 2012, Kawai et al., 2013) caused extensive damage to coastal areas. Hurricanes and typhoons have also historically caused catastrophic damage and loss of life across the globe. Recent examples include Typhoon Haiyan (e.g. Tajima et al., 2014, Mori et al., 2014), Hurricane Sandy (e.g. Fanelli et al., 2013, Blake et al., 2013), and Hurricane Katrina (e.g. Robertson et al., 2007, van de Lindt et al., 2007). In the United States alone, seven of the ten costliest disasters since 1980 have been caused by hurricanes (Lackey, 2011).

These coastal hazards emphasize the need to understand the fundamental processes causing damage in order to provide increased resilience to hurricane or tsunami events. 
However, on a local scale, engineers must consider site-specific characteristics to creatively employ hazard-mitigation methods that most effectively defend a particular community. Close to shore, a tsunami will be affected by the local bathymetry and tides, which can increase or decrease tsunami runup and inundation. As tsunamis approach shore, runup processes may be observed as a rushing bore or group of bores; for steeper beachfront slopes, a tsunami may cause a gradual rise and fall of the water level, and in some situations (e.g., the 1946 Aleutian Tsunami), a tsunami may form a collapsing breaker directly at the shoreline (Yeh, 2009). Seawalls, breakwaters, and vegetated dunes successfully or partially protected inland communities off the epicenter in the 2011 Tohoku Earthquake Tsunami and during Hurricane Sandy, while communities in other areas sustained near-complete destruction (Suppasri et al., 2013a, Nandasena et al., 2012, Irish et al., 2014). However, details of hydrodynamic transformation and forces as flows propagate through urban communities are still not well understood at both the research and design levels.

\subsection{Previous Tsunami and Hurricane Investigations}

Common methods used to evaluate local conditions caused by tsunamis and hurricanes include post-disaster reconnaissance field surveys, numerical modelling, and laboratory experiments. After a tsunami or hurricane, field surveys are useful in assessing damage and measuring runup and high water marks (e.g. Mori et al., 2011). Such surveys have led to the development of empirical fragility models that relate inundation height, structural characteristics, and other hindcast variables to a structure's probability of 
damage (Suppasri, et al., 2012, Suppasri, et al., 2013b, Tomiczek et al., 2014, Tomiczek et al., 2016). However, it is often difficult to estimate water velocities or forces on structures from post-disaster survey data. In addition to on-site surveys, numerical models such as ADCIRC (Luettich et al., 1992), SLOSH (Jelesnianski et al., 1992) for storm surge, SWAN (Holthuijsen et al., 1993) for wave spectral modelling, FUNWAVE (Wei and Kirby, 1995), COULWAVE (Lynett et al., 2008), and NHWAVE (Ma et al., 2012) for phase resolving wave modelling, have been developed to simulate hurricane conditions or tsunami propagation over local topographies. These models require validation and refinement to reliably predict overland wave dissipation. Often, numerical models remove structures and use land-use-based roughness coefficients rather than explicitly modelling the complex wave-structure interaction, leading to errors in model outputs (e.g. Westerink et al., 2008, Dietrich et al., 2012). Therefore, wave models, vulnerability assessments, and damage prediction techniques must be refined to account for wave interaction with individual structures and groups of structures to design resilient coastal communities.

Laboratory experiments are an essential starting point in understanding urban roughness effects on hydrodynamic phenomena. Historical experiments have provided valuable datasets that have been used to validate numerically-simulated water velocities and water surface elevations, as well as to derive empirical Manning's $n$ or roughness coefficients (e.g. Goto and Shuto, 1983, Synolakis, 1987, Briggs et al., 1995, Liu et al., 1995, Chen et al., 2007, Baldock et al., 2009). Goto and Shuto (1983) determined Manning's $n$ values for tsunami flow through various configurations of vertical cylinders; however, Mannings 
$n$ values for tsunami flow through urban areas and forests have been found to be too small (Bricker, 2015). Other tests have focused on tsunami characteristics, as breaking wave solutions differ significantly from the nonlinear shallow water equations for nonbreaking waves. To simulate tsunami profiles during the 2004 Indian Ocean Tsunami that showed breaking initial wave fronts, Baldock et al. (2009) performed experiments to measure water surface elevations, water velocities, and wavemaker displacements for breaking tsunami wave conditions. These experiments were forced using solitary wave conditions at the O.H. Hinsdale Wave Research Laboratory at Oregon State University. Goseberg et al. (2013) presented a thorough review of the state-of-the-art of these and other tsunami generation techniques including that by piston-type paddle, dam break, vertical wave board motion, and pneumatic wave generation, as well as limitations of such models.

Recent tests have further investigated wave propagation through urban environments (e.g. van de Lindt et al., 2009, Cox et al., 2008, Goseberg and Schlurmann, 2012, Goseberg, 2013). Measurements by Thomas et al. (2015) and Irish et al. (2014) found that macroroughness elements, defined herein as groupings or arrays of large scale obstacles like buildings, seawalls, or forested areas, lead to increased protection in wake areas where waves are reflected and flow is diverted. However, structures in narrow regions are subject to flow amplification and increased hydrodynamic forces. Experiments on scale models of real cities have also been used to validate numerical models. Cox et al. (2008) generated a dataset of tsunami flow over and around a 1:50 idealization of Seaside, Oregon and showed that both the COULWAVE (Lynett et al., 2002) and STOC-IC 
(Tomita et al., 2006, Tomita and Honda, 2009) numerical models were able to capture many features of flow. Park et al. (2013) compared these data with predictions of water velocity, free surface elevation, and momentum flux from the COULWAVE model (Lynett et al., 2002). Few physical models have further addressed the role of shielding in reducing tsunami-induced run-up and pressures on inland structures. Goseberg (2013) analyzed effects of beachfront developments on reducing the maximum run-up of sinusoidal waves, while the effects of low-height mitigation walls on forces induced by tsunami bores were evaluated by Al-Faesly et al. (2012). Thomas and Cox (2012) extended the work of Oshnack et al. (2009) to show that small seawalls generally reduced the maximum tsunami load on a specimen, although local pressures were sometimes increased. Thomas and Cox (2012) developed empirical formulas for predicting reduction factors for the maximum tsunami force based on the incident tsunami and in-situ seawall characteristics.

\subsection{Remaining Questions and Experimental Scope}

While the abovementioned tests have been useful and indicate progress toward robustly and accurately modelling wave-structure interaction, all were performed with idealizations of the tsunami wave profile. Many experiments have modelled tsunamis using solitary waves (e.g. Cox et al., 2008, Thomas and Cox, 2012, Park et al., 2013); however, Madsen et al. (2008) showed that solitary waves may not be suitable representations of real-world mega tsunamis due to upscaling discrepancies in wavelengths and periods between model and prototype. Recent works are using 
alternative methods of wave generation to creatively address the issue of modelling tsunamis in the laboratory (e.g. Rossetto et al., 2011, Goseberg, 2013). For example, Rossetto et al. (2011) validated a pneumatic tsunami generator that is capable of creating solitary waves and leading-depression $\mathrm{N}$-waves with large wavelengths; the wavemaker was able to reproduce a time record of the 2004 Indian Ocean Tsunami off the coast of Thailand. Goseberg et al. (2013) used a novel pump-driven wave maker that produced prolonged sinusoidal and leading-depression $\mathrm{N}$ waves with periods of $15-120 \mathrm{~s}$, thus resulting in more realistic prototype tsunami durations. Experimental results compared well with outputs from a numerical model time series of a tsunami water surface elevation in $30 \mathrm{~m}$ depth. Bremm et al. (2015) similarly used this volumetric wavemaker to investigate the drag and inertial forces on an aluminum specimen caused by long, leading-depression waves. These waves show better agreement between model and prototype time scales; however, they still simplify the tsunami profile. Water surface measurements recorded by GPS buoys during the 2011 Tohoku Earthquake Tsunami showed complex profiles consisting of waves with shorter periods and sharp peaks embedded in a longer time scale water level rise (Kawai et al., 2012, Kawai et al., 2013).Laboratory experiments simulating complex wave conditions may thus provide a clearer understanding of tsunami propagation in the presence of macro-roughness elements. The goal of the current experiment was to generate complex offshore wave conditions involving combinations of short- and long-period waves to characterize the effects of incident wave characteristics in changing hydrodynamic phenomena around varying structural configurations. Benchmark data was collected at Kyoto University on a 1:20 length scale physical model to address this question. 
The remainder of this work is organized as follows: section 2 describes the hydraulic flume, instrumentation, and experimental program. Results are presented in section 3, and the effects of incident wave conditions and macro-roughness elements on changing the maximum pressure on an idealized structure are described. Section 3 also characterizes the tsunami waveforms recorded by GPS buoys during the 2011 Tohoku Earthquake Tsunami and compares those to waves created in the current experiment. Finally, section 4 addresses successes and limitations of the hydraulic flume and areas for future research before highlighting major conclusions and offering engineering recommendations for damage mitigation.

\section{Instrumentation and Experimental Conditions}

\subsection{Hydraulic Wave Flume}

Experiments were conducted at Kyoto University’s Hybrid Tsunami Open Flume in Ujigawa Laboratory (HyTOFU), which has dimensions $45 \mathrm{~m}$ x $4 \mathrm{~m}$ x $2 \mathrm{~m}$ high and a design water depth of $0.8 \mathrm{~m}$. In this experiment all wave conditions were imposed on a constant water depth of $0.700 \mathrm{~m}$. Figure 1 depicts plan and profile views of the wave flume and shows the coordinate system used in analysis, with waves propagating in the positive $x$-direction from $x=0$ at the wavemaker's origin. The $y$-coordinate system was defined from the west wall of the flume and oriented alongshore, and the $z$-axis was

defined positive upwards from the bed of the flume. The flume bed and side walls were 
constructed of smooth concrete (Manning's $n=0.0013$, ODOT, 2014), with two $4 \mathrm{~m}$ long glass panels installed in the side walls. Upon generation, waves propagated across the smooth concrete bed of length $14.05 \mathrm{~m}$ and then up a $7.95 \mathrm{~m}$ long 1:10 planar slope before reaching the flat beach surface elevated $0.095 \mathrm{~m}$ above the stillwater level, where structural elements were positioned. The planar slope and flat beach were made of iron and coated with an anti-rust paint. At the end of the flat beach, flow propagated into an open drain and into a side channel with dimensions $30 \mathrm{~m}$ x $4 \mathrm{~m} \times 2 \mathrm{~m}$ high, which allowed water to be cycled during pumping conditions.

The 1:10 planar slope is representative of a steep beach profile and is similar to beachfront slopes reported by Reis and Gama (2010). While beachfront slopes as steep as 1:5 have been documented (McLachlan and Dorvlo, 2005), most real-world beaches can be characterized by gentler slopes between 1:50-1:200. Based on the flume dimensions, a length scale of 1:20 was chosen, and offshore water surface perturbation target heights were chosen to be between 0.4-0.5 m, corresponding with prototype wave heights of 8-10 $\mathrm{m}$, similar to the maximum tsunami water levels in Miyako point $(8.5 \mathrm{~m})$, Ayukawa point (8.6 m), and Soma point (9.3 m) observed in eastern Japan during the 2011 Tohoku Earthquake Tsunami (Japanese Cabinet Office (JCO), 2011). The range of wave conditions generated in this experiment, combined with the flume bathymetry, created a variety of onshore runup conditions.

The flume is capable of three types of wave generation: a constant-flow pump, a mechanical piston, and a vertical discharge of a constant volume of water from a set 
elevation above the free surface. A pump with a $70 \mathrm{Kw}, 980 \mathrm{rpm}$ motor discharges a constant flow from two $2 \mathrm{~m}$ x $0.2 \mathrm{~m}$ sized outlets at the bed to produce a slow increase in water level similar to that associated with a tsunami or a typhoon-induced storm surge. The maximum pumping capacity is $0.83 \mathrm{~m}^{3} / \mathrm{s}$, with a maximum operating time of 1200 seconds. A piston-type, mechanical paddle with maximum stroke of $2.5 \mathrm{~m}$ and a maximum moving speed of $2.827 \mathrm{~m} / \mathrm{s}$ is capable of generating a solitary wave with a maximum height of $0.5 \mathrm{~m}$, regular waves with heights up to $0.35 \mathrm{~m}$, and irregular waves using the Bretshneider-Mitsuyasu, JONSWAP, or 5-Parameter spectral functions. The final method of wave generation involves dropping a constant volume of water from a set elevation above the free surface in a variation of the dam-break analogy, similar to a technique described by Chanson et al. (2003); however, this method was not used in the current experiment.

Individually, the wave generation mechanisms in HyTOFU can create breaking or nonbreaking waves similar to those generated in previous experiments (e.g. Cox et al., 2008, Thomas and Cox, 2012, Goseberg et al., 2013, Bremm et al., 2015). However, creative combinations of the mechanical and pumping generation mechanisms can create waves that resemble the recent complex tsunami traces observed after the 2011 Tohoku Earthquake Tsunami. A computerized-synchronization program of all three wavegeneration mechanisms triggers the superposition of piston-generated waves onto the pump-generated flow after a specified duration. Inputs into the program include the desired pumping flow rate $\left(0-0.83 \mathrm{~m}^{3} / \mathrm{s}\right)$, the target solitary wave height $(0-0.5 \mathrm{~m})$, and the duration of pumping flow before solitary wave generation. In this experiment, pump 
flow was generated for 180 seconds, and a mechanically-generated wave was superimposed over the pumping flow after 60 seconds. Table 2 shows the inputs into the synchronization program for mechanical target wave heights and pump flow rates for this experiment; seven combinations of inputs were tested to create a constant total offshore water surface perturbation with varying wave characteristics ranging from a strong constant flow to a nearly pure solitary wave.

\subsection{Structural Elements and Pressure Measurements}

Acrylic and steel structural elements represented coastal residences. Based on the 1:20 experimental length scale, the dimensions of the structural elements $(0.40 \mathrm{~m} \mathrm{x} 0.40 \mathrm{~m} \mathrm{x}$ $0.50 \mathrm{~m}$ high) correspond to a relatively narrow house that may be found in a typical Japanese coastal community ( $8 \mathrm{~m} \times 8 \mathrm{~m} \times 10 \mathrm{~m}$ high). The underside of the specimen was coated with a thin rubber mat ( $<1 \mathrm{~mm}$ thickness) and the specimen was weighted to the bottom using $>100 \mathrm{~kg}$ weights. The specimen's location in the flume was marked to ensure that wave impact did not induce movement, though field surveys have noted that entire structures may be dislodged from their foundations and washed away during a tsunami (Gokon and Koshimura, 2012). Pressure sensors with a $50 \mathrm{kPa}$ rated capacity

were installed at elevations above the base of the structure $0.01 \mathrm{~m}, 0.05 \mathrm{~m}$, and $0.15 \mathrm{~m}$ on the front, lateral, and back sides of the instrumented specimen as shown in Figure 2. Figure 3 shows a photograph of wave gauges and Acoustic Doppler Velocimeters (ADVs) installed in the flume, as well as a frontal view of the instrumented specimen with mounted pressure gauges and a nearby wave gauge and ADV. 
Pressure time series were recorded at a frequency of $200 \mathrm{~Hz}$ and cleaned to remove contamination by local utility frequencies $(60 \mathrm{~Hz})$ using a low pass filter for frequencies less than $50 \mathrm{~Hz}$. Cleaned data was checked for sensitivity to frequency components; filtered and unfiltered peak pressure recordings differed by less than 5\%. A sample time series of the pressure measured $0.01 \mathrm{~m}$ above the base of the structure on the centerline of each of the front, lateral, and rear faces of the instrumented specimen is shown in Figure 4 for Trial 7, with the obstacle positioned $2.39 \mathrm{~m}$ from shore. The wave induces peaks in the frontal pressure time series; the first peak corresponds with the short-duration impact of the wave, and the second peak is due to the quasi-hydrostatic pressure exerted by the standing wave, as has been observed in previous experiments (e.g. Fujima et al., 2009, Bradner et al., 2009, Thomas and Cox, 2012). While other tests focusing on the pressure impulse have successfully used higher sampling rates between 400-10000 Hz (e.g. Wood et al., 2000, Bullock et al., 2007), Cooker (2002) reported that at full scale the main pressure impulse typically lasts $\sim 100 \mathrm{~ms}$. For a 1:20 length scale and Froude similarity, the frequency used in experiments was enough to capture the duration of the main pressure spike, which at model scale would be predicted to last 0.022 seconds. In the current experiments, sensitivity tests run using recording frequencies of $500 \mathrm{~Hz}$ and 1000 $\mathrm{Hz}$ indicated that a sampling frequency of $200 \mathrm{~Hz}$ was sufficiently able to capture the pressure spike due to the impulsive wave load while optimizing the operation of the recording software. Wave-induced pressure impulse is a subject of active research, and has been difficult to characterize; the impulsive pressure itself has been shown to be sensitive to the wave shape immediately before impact (Oumeraci et al., 1993, Hattori et 
al., 1994, Cooker and Peregrine, 1995, Peregrine, 2003). Wood et al. (2000) found that the compressibility of entrained air in breaking waves can affect wave-structure dynamics and the maximum pressure. Bullock et al. (2007) analyzed conducted pressure impulse experiments on a 1:4 physical model and distinguished between low aeration impacts, with short durations and high pressure spikes, and high aeration impacts, with longer durations and less localized pressure peaks. While at large scales aeration can affect the maximum impulsive pressure, for the smaller length scales of these experiments aeration effects become small. The pressure impulse, defined as the integral of the pressure time series over the duration of the impulsive pressure spike, has shown less sensitivity to the incident wave shape (Cooker and Peregrine, 1995, Cooker, 2002, Peregrine, 2003); however the scope of this paper focuses on the single maximum recorded pressure, which can be integrated to estimate the load on the face of the experimental specimen. For all experiments, the maximum pressure was recorded by a frontal pressure gauge, typically due to the wave impact. Bradner et al. (2009) noted that for large bridges the high amplitude of these pressure spikes may not be felt by structural supports due to the short duration of impact and the large inertia of the test specimen. However, this impact pressure can cause significant localized damage and cannot be neglected. Thus, the present analysis defined the critical pressure as the maximum pressure recorded on the front face of the structure.

\subsection{Surface Elevation Measurements}


Wire resistance wave gauges recorded the time series of water surface elevation $\left(\eta_{\text {wave }}+\eta_{\text {flow }}\right)$ above the local initial water depth at varied locations along the flume, where $\eta_{\text {wave }}$ and $\eta_{\text {flow }}$ are the water surface elevation increases generated by the mechanical paddle and pumping flow mechanisms, respectively. Stationary offshore wave gauges, WG1-WG5, were positioned along the centerline of the flume with distances from the mechanical paddle's origin shown in Figure 1. These gauges were used to define wave characteristics and to check the repeatability of the wave form. Onshore wave gauges, WG6-WG10, were moved for each experimental configuration; these wave gauges were positioned $0.10 \mathrm{~m}$ from the front, lateral, and rear faces of the instrumented structural element. Figures 5 and 6 show the nine experimental configurations tested, and Table 1 provides the $x$-locations of onshore wave gauges for each configuration. The flow velocity was recorded using four Nortek Vectrino ADVs installed within the array of structural elements and offshore at $x=17.50 \mathrm{~m}$ (see Figures 5 and 6). However, ADV measurements, especially onshore ADV data, were affected by low water levels and breaking-wave turbulence. Therefore, the wave signal was often difficult to extract from noise, and velocity measurements are not considered in the present analysis.

\subsection{Experimental Conditions}

Table 2 lists the seven combinations of wave conditions that were imposed on each of the nine configurations of structural elements. In all trials, the mechanically-generated wave was generated 60 seconds after the onset of pumping flow. For clarity, the remainder of the paper designates each combination of inputs as a "trial," while a specific wave 
condition generated across a specific configuration is termed "test". Input wave conditions were selected to generate an almost constant offshore total perturbation above the initial stillwater depth of $0.700 \mathrm{~m}$ with varying contributions due to the mechanical wave $\left(\eta_{\text {wave }}\right)$ and constant flow $\left(\eta_{\text {flow }}\right)$. Offshore water surface profiles for WG1-WG5 for both tests run in all trials for configuration 3 , as well as definitions of $\eta_{\text {wave }}$ and $\eta_{\text {flow }}$, can be seen in Figure 7. For increasing mechanical waves, the height of the solitary wave relative to the total water surface perturbation increased for all offshore wave gauges; however, with the exception of Trial 7, increased mechanical wave inputs were paired with decreased pumping flow inputs to generate similar maximum offshore water surface elevations. Two tests were conducted for each trial-configuration combination to check the repeatability of the wave profile. For each of the 18 tests conducted for each trial, the ensemble average of the total water surface perturbation at WG2, positioned near the toe of the sloping beach is listed in Table 2. The total offshore water level perturbation was typically between 0.40 and $0.43 \mathrm{~m}$; Trial 7 resulted in offshore perturbations about $15 \%$ larger than those generated in other trials. Based on the length scale used during experiments, offshore water surface elevations correspond to prototype scale perturbations 8-9.5 m above the mean water depth. Tests were conducted 15-20 minutes apart to allow the water surface to calm and to dry the flat beach and structural elements using squeegees and towels. Table 2 shows that for each trial, $\left(\eta_{\text {wave }}+\eta_{\text {flow }}\right)$ measurements were repeatable for all configurations; standard deviations of water surface elevation records between repeated tests were between 0.0015-0.0172 $\mathrm{m}$, much smaller than the wave signal. The slightly larger standard deviation in the water surface profiles for trials with larger pumping inputs are due to greater wave reflection in Trials 4-9. 


\section{Results and Discussion}

\subsection{Offshore Wave Characterization}

Initial analysis examined the effects of the ratio of the solitary wave height $\left(\eta_{\text {wave }}\right)$ to the total water surface perturbation due to the pumping flow and mechanical wave $\left(\eta_{\text {wave }}+\eta_{\text {flow }}\right)$. The inputs from Trials 1-7 in Table 2 increased the amplitude of the solitary wave with respect to the constant flow water surface increase; for unobstructed configurations, the obstacle's setback distance from shore was also varied. These variations affected wave breaking characteristics with respect to the instrumented specimen, which changed the maximum pressure on the front face of the unobstructed obstacle for each setback configuration. Pressure was nondimensionalized using either the hydrostatic pressure of the offshore disturbance or the local, bare-earth water surface elevation recorded in a control, zero-obstacle configuration:

$$
\begin{aligned}
& p_{i}^{*}=\frac{p_{i}}{\rho g\left(\eta_{\text {wave }, i}+\eta_{\text {flow }, i}\right)_{\max }} \\
& \text { or } \\
& p_{i}^{* *}=\frac{p_{i}}{\rho g\left(\eta_{b e, i}\right)_{\max }}
\end{aligned}
$$

In Equations (1) and (2), $p_{i}{ }^{*}$ is the nondimensionalization of the measured pressure $p_{i}$ at time step $i$ using the offshore water surface perturbation at WG2 $\left(\eta_{\text {wave }}+\eta_{\text {flow }}\right)$ and $p_{i} * *$ is the nondimensionalization using the bare-earth water surface elevation at the location of the structure $\left(\eta_{b e}\right)$. Other variables in the above equations are the density of water, $\rho$, 
taken as $1000 \mathrm{~kg} / \mathrm{m}^{3}$ for freshwater used in experiments, and the gravitational acceleration, $g$. Nondimensionalization of pressure using the different water surface elevations reflects different wave properties. The offshore water surface elevation characterizes wave conditions before waves are affected by shoaling or macro-roughness elements, while the local bare-earth water depth is a common parameter output by numerical models and used to estimate maximum pressures and loads in design guidelines (e.g. JCO, 2005, ASCE, 2016).

Wave characteristics at WG2 were also used to parameterize incoming waves. These incident signals of offshore waves may be readily reproduced by models, and thus may be used to simulate experiments for future studies. Understanding how offshore wave characteristics affect onshore wave behavior is of significant interest for structural design. Additionally, these conditions are comparable to data recorded by offshore buoys during the 2011 Tohoku Earthquake Tsunami (NOWPHAS, 2011). In experimental analyses, the water surface perturbation generated by pumping flow, $\eta_{\text {flow }}$, above the local stillwater depth was recorded at the time just before the quick rise caused by the mechanicallygenerated wave. The solitary wave perturbation, $\eta_{\text {wave }}$, was then calculated by subtracting $\eta_{\text {flow }}$ from the maximum recorded water surface perturbation; Figure 7 shows the definitions of $\eta_{\text {flow }}$ and $\eta_{\text {wave }}$ for Trial 4 . The ratio of $\eta_{\text {wave }}$ to the total water surface perturbation, $\eta_{\text {total }}=\left(\eta_{\text {wave }}+\eta_{\text {flow }}\right)$ was defined as the solitary wave fraction, $\eta^{*}$ :

$$
\eta^{*}=\frac{\eta_{\text {wave }}}{\eta_{\text {wave }}+\eta_{\text {flow }}}
$$

Therefore, $\eta^{*}=0$ for a constant flow with no superimposed solitary wave, while $\eta^{*}=1$ for a solitary wave with no initial increase in water level. 
Although $\eta^{*}$ can be readily defined for this experiment, the choice of $\eta^{*}$ depends on the somewhat arbitrary designation of $\eta_{\text {flow }}$. Therefore, surge conditions and definitions require further discussion, particularly for field applications. A dimensionless rise time ratio, $t^{*}$, comparing the periods of the slow and fast rise waves, was thus introduced as an additional parameterization of $\eta^{*}$ :

$$
t^{*}=\frac{t_{\text {slow }}}{t_{\text {total }}}
$$

In the above definition, $t_{\text {slow }}$ measures the time from the beginning of the tsunami signal, $t_{0}$, to the local peak due to the slow water surface rise, and $t_{\text {total }}$ measures the time from $t_{0}$ to the maximum water surface elevation. Trial 1 involved only pump-generated flow; therefore, $\eta_{\text {flow }}=\eta_{\text {total }}$ and $t_{\text {slow }}=t_{\text {total }}$, so $\eta^{*}=0$ and $t^{*}=1$. For all other experimental conditions, $\eta_{\text {flow }}$ was generated for 60 seconds after the start of the experiment $\left(t_{0}\right)$ before the mechanical wave was produced, and the mechanical wave was recorded by WG2 shortly after its generation. The fast rise time was relatively consistent for the solitary wave, so $t_{\text {slow }}$ was only a few seconds shorter than $t_{\text {total }}$. Because of these experimental controls, $t^{*}$ was almost constant for offshore wave gauges (WG1, WG2, WG3, and WG4) across all trials $\left(t^{*}{ }_{a v g}=0.972\right)$. Variations in flow rate were not reflected in experimental $t^{*}$ calculations.

Note that the slow rise time and total rise time of a real tsunami may be expected to vary depending on an earthquake's rupture characteristics, causing more variation in $t^{*}$ in the field than in the present experiment. Therefore, $t^{*}$ and $\eta^{*}$ were determined for the tsunami waveforms recorded by GPS buoys GB801, GB802, GB803, GB804, GB806, 
and GB807 during the Tohoku Earthquake Tsunami on March 11, 2011 (NOWPHAS, 2011). Table 3 provides the location and depth for each field gauge, and Figure 8 shows the water surface profiles and the methodology for determining $t^{*}$ and $\eta^{*}$. The initial time at which the water surface began to rise varied for each GPS buoy; therefore, $t_{0}$ was identified as the trough in the water surface profile before the slow and quick rises in the tsunami waveform. To determine the local peak and the onset of the quick rise wave, $\eta_{\text {flow }}$ was defined to be consistent with analyses performed on these data by Kawai et al. (2013). Kawai (2013) characterized the tsunami waveform at these buoys by considering the ratio of the elevation of a local peak occurring after a slow rise, $h_{l}$ to the height of the total wave crest, $h_{w}$. This ratio is essentially the complement of $\eta^{*}$ defined here:

$$
\eta^{*}=\frac{\eta_{\text {wave }}}{\eta_{\text {total }}}=1-\frac{\eta_{\text {flow }}}{\eta_{\text {total }}}=1-\frac{h_{l}}{h_{w}}
$$

Calculations of $\eta^{*}$ and $t^{*}$ were made for each buoy and are plotted with experimental data from WG1, WG2, WG3, and WG4 in Figure 9. As shown in Figure 9, field gauges show a generally decreasing trend in $t^{*}$ with increasing $\eta^{*}$, with GB801 recording a dimensionless rise time very similar to those generated in experiments. For a given tsunami event, the ratio of slow rise time to fast rise time will affect the solitary wave ratio. The variation of $t^{*}$ and $\eta^{*}$ with location for the Tohoku Earthquake Tsunami traces suggests that the rate of slow water level increase was relatively consistent for all latitudes; therefore, $t^{*}$ may give insight into wave and flow characteristics when $t_{0}$ is varied. The decreasing trend of $t^{*}$ with $\eta^{*}$ for a given event makes intuitive sense: as the tsunami profile approaches a solitary wave $\left(\eta^{*}=1\right)$, there should be no slow rise before the initial crest; hence $t_{\text {slow }}$ and thus $t^{*}$ approach 0 . Likewise, for a purely constant slowrise increase $\left(\eta^{*}=0\right), t_{\text {slow }}$ approaches $t_{\text {total }}$, making $t^{*}$ approach 1 . Note that for GPS buoys 
north of $38^{\circ} \mathrm{N}$ latitude, $\eta^{*}$ increased and $t^{*}$ decreased with increasing latitude.

Comparisons with runup and inundation data obtained by Mori and Takahashi (2012)

indicated that the northern buoys GB802, GB804, and GB807, which recorded $\eta *>0.6$, were offshore of regions that experienced the highest measured tsunami runup and inundation heights. Local bathymetry and topography certainly affected tsunami runup and inundation; additionally, the flume geometry and availability of field data caused a discrepancy between prototype and model water depths. However, the offshore wave gauge data in the flume may cautiously be compared with these field data as the wave was not affected by the flume slope at measurement locations, and general trends may be compared to prototype effects. For example, this analysis may indicate that an offshore solitary wave ratio above 0.6 corresponds with more severe onshore tsunami effects. Such characterizations must be tested under other experimental conditions and in analyses of other field data or numerical model outputs to further examine the effects of varying $t^{*}$ and $\eta^{*}$.

\subsection{Solitary Wave Ratio Effects on Pressure}

Figure 10 depicts the relationship between $p^{*}, p^{* *}$, and $\eta^{*}$ for each setback distance, and Table 4 presents the elevation of the pressure gauge which recorded the maximum pressure. Trials with large pumping inputs and small mechanical wave inputs corresponded with low values of $\eta^{*}$ and were observed to propagate past the obstacle as nonbreaking waves for all setback distances. As seen in Figure 10a, these trials showed a near 1:1 agreement between the maximum pressure and the nearshore hydrostatic 
pressure caused by the wave and flow perturbation. The largest pressure was recorded by a pressure gauge positioned near the base of the structure, indicating that hydrostatic pressures may dominate for nonbreaking waves.

In contrast to nonbreaking conditions, waves that broke on or just in front of the obstacle significantly changed the magnitude and location of maximum pressure recordings. Breaking was confirmed visually during experiments and with video recordings. In particular, for unobstructed configurations, the waves of Trials 6-7 were observed to break just before the flat beach. The wave generated in Trial 5 broke almost directly on the specimen positioned $L_{I}=0.79 \mathrm{~m}$ from shore, while the wave of Trial 4 broke just before the specimen positioned at setback distance $L_{2}=1.59 \mathrm{~m}$. Trials $1-3$ propagated unbroken past the obstacle at all three setback distances. Extreme pressures were recorded when waves broke directly onto or very close to the instrumented specimen; as an example, consider in Figure 10a the wave of Trial 4, with offshore solitary wave fraction $\eta^{*}=0.51$. This wave propagated unbroken past the specimen positioned at $L_{1}=0.79 \mathrm{~m}$, the closest setback configuration. However, it broke almost directly on the obstacle positioned at $L_{2}=1.59 \mathrm{~m}$. As the wave transformed from an unbroken wave at $L_{1}$ to a breaking wave at $L_{2}$, pressure increased from $p_{1} *=1.37$ to $p_{2} *=3.79$, an increase of 176\%. Also note in Table 4 that the location of maximum pressure recorded by the specimen changed from near the base of the structure (local elevation $0.05 \mathrm{~m}$ above the flat beach) at $L_{1}$ to an elevation $0.15 \mathrm{~m}$ above the base of the structure at $L_{2}$, which was the highest elevated position of pressure gauges. When the specimen was positioned at $L_{3}=2.39 \mathrm{~m}$, this wave propagated past the obstacle as a turbulent bore and generated a 
pressure $p_{3} *=2.17$ : less than that of the just-breaking wave at $L_{2}$ but still $59 \%$ larger than the unbroken wave pressure at $L_{1}$. Next, consider the wave of Trial $5(\eta *=0.64)$, which broke over $0.8 \mathrm{~m}$ closer to shore, almost directly before the obstacle positioned at $L_{1}=0.79 \mathrm{~m}$. This wave, with a larger wave solitary fraction, induced a larger pressure at the structure at $L_{I}\left(p_{1} *=4.49\right)$ than waves that broke further inland. Note that this wave dissipated energy before impacting the obstacle positioned at $L_{2}$ or $L_{3}$; this dissipation due to wave breaking was reflected in a sharp drop in the pressure recorded on the instrumented specimen with respect to the offshore water surface perturbation for these two setback distances, as indicated in Figure 10a. Thus, for houses positioned near the shoreline, breaking waves may induce larger forces than waves which break on inland structures. However, if waves break further inland, shoreward structures may not necessarily expect reduced pressures. Furthermore, wave breaking affects the vertical location of maximum pressure on a coastal structure; this spatial variation must be considered in the design of coastal residences.

While Figure 10a reflects the maximum pressure with respect to the relatively constant offshore water surface perturbation, Figure 10b shows the increasing contribution of dynamic wave impact to the maximum pressure with an increasing solitary wave fraction $\eta^{*}$. As $\eta^{*}$ increased, the local water surface elevation decreased due to the wave breaking closer to the shoreline. The waves of Trials 6-7 propagated across the bare beach as lowelevation turbulent bores with water surface elevations $0.15-0.16 \mathrm{~m}$ at $L_{l}, 0.09-0.10 \mathrm{~m}$ at $L_{2}$, and 0.06-0.07 $\mathrm{m}$ at $L_{3}$. The dimensionless pressure $p^{* *}$ with respect to these low water surface elevations increased greatly relative to the equivalent hydrostatic pressure 
at these locations. This is a significant finding because many design equations use the local bare-earth water surface elevation when estimating the maximum tsunami-induced pressures and forces on a structure. For example, the equation proposed by Asakura et al. (2000) and recommended by the JCO (2005) for tsunami design estimates the maximum pressure at a given elevation $\left(z_{i}\right)$ above the ground $\left(z_{g}\right)$ caused by a tsunami with no initial water level increase (e.g. $\left.\eta_{f l o w}=0\right)$ as $p=\rho g\left(3 \eta_{b e^{-}} z\right)$. For $z_{i}-z_{g}=0$, solving for the dimensionless pressure $p^{* *}$ in the equation gives $p^{* *=} p / \rho g\left(\eta_{b e}\right)=3$, indicating that $p^{* *}$ should converge to a value near 3 for a tsunami with characteristics of a solitary wave. While the equation produces conservative estimates for nonbreaking wave trials, Figure 10b shows that the pressures measured for Trials 6 and 7 reach 10-20 times the hydrostatic approximation for the setback distances considered. Therefore, an idea of the wave characteristics (e.g. breaking or nonbreaking) or a consideration of wave-structure interaction must be incorporated into design to account for the contribution of impulsive wave pressures to the total structural load. While Figure 10b shows pressures much greater than the local hydrostatic pressures, Figure 10a shows that the maximum pressure with respect to the total offshore water surface perturbation $\left(p^{*}\right)$ was registered when waves broke on or just before the structure. After this maximum pressure, increasing the solitary wave ratio $\eta^{*}$ decreased $p^{*}$. For the largest values of $\eta^{*}, p^{*}$ converges to a value just above 3, which more closely matches the equation proposed by Asakura et al. (2000).

\subsection{Setback Distance Effects}


The three setback distances considered in configurations 1-3 were normalized by the offshore water surface perturbation to parameterize the setback distances considered here: $L_{i}^{*}=L_{i} /\left(\eta_{\text {wave }}+\eta_{\text {flow }}\right)$. The effects of this normalized setback parameter are shown in Figure 11, which plots $p^{*}$ against $L^{*}$ for the $\eta^{*}$ corresponding to each trial of Table 2. Figure 11 provides further evidence that unbroken waves, characterized by $\eta^{*}<0.40$, do not produce large impulsive pressures on structures. However, turbulence and impact associated with wave breaking are identified as sharp spikes in maximum pressure and show that impulsive loading can induce critical pressures on a coastal structure. Figure 11 shows sharp pressure peaks when wave breaking occurred closest to the obstacle; these conditions occurred for $L_{1}=0.79 \mathrm{~m}\left(L_{1} *=2.00\right)$ at $\eta^{*}=0.64$ (Trial 5) and for $L_{2}=1.59 \mathrm{~m}$ $\left(L_{2}{ }^{*}=3.93\right)$ at $\eta^{*}=0.51$ (Trial 4). For both trials, positioning the specimen $0.80 \mathrm{~m}$ further inland resulted in decreased pressures for the same wave conditions. For example, experiments with $\eta^{*}=0.64$ caused a maximum pressure $p^{*}=4.49$ at $L_{l}$, but increasing the setback distance to $1.59 \mathrm{~m}$ for the same trial decreased the maximum pressure by $49 \%$ $\left(p^{*}=2.29\right)$. Therefore, estimation of tsunami force is highly sensitive to a structure's nearshore location, and the maximum pressure may be reduced when an obstacle is further removed from the breaking point of the first wave peak.

\section{4. Macro-Roughness Effects}

In addition to varying setback distance, nine structures were positioned in the $3 \times 3$ arrays shown in Figure 6 to evaluate the effects of macro-roughness elements on wave transformation and maximum pressures. As shown in Figure 6, two configuration 
variables were considered: (1) location of measurement specimen (first, second, or third row), and (2) spacing between obstacles $(0.40 \mathrm{~m}$ or $0.20 \mathrm{~m})$. Water surface elevation and pressure recordings for each trial were compared to those for unobstructed configurations. Figure 12 compares water surface profiles with one structure and with nine structures at locations B1-B4 shown in Figures 5 and 6. Specifically, the water surface elevations from configuration 1 were compared with those obtained from wave gauges in similar positons in macro-roughness tests from configurations 4 and 6 (0.2 $\mathrm{m}$ spacing) and configurations 7 and 9 (0.4 m spacing). The authors note slight differences $(<0.2 \mathrm{~m})$ in the exact distance from shoreline for wave gauge comparisons; however, differences in water surface elevation were due to structural interference with wave propagation, not overland wave dissipation. As shown in the figure, just offshore of the array of structures, the water surface profile is nearly identical to that in front of the unobstructed specimen; trials involving large pumping flow rates were characterized by greater flow reflection in macro-roughness configurations and thus greater water surface elevations in front of the array of structures. These observations echo those of Goseberg et al. (2008) who showed that modelled tsunami water levels were significantly increased in front of build environments. Between rows, the effects of macro-roughness elements on the water surface profile become apparent. In particular, behind the first row of obstacles, wave interaction with nearby structures increased the maximum water surface elevation, showing similar heights to those recorded in front of the array of structures. However, increasing rows of protection caused water surface dissipation. For the wave of Trial 7 , comparison of the water surface profiles shielded by one row (B2) indicates that the maximum water surface elevation was larger for the array with $0.20 \mathrm{~m}$ spacing $(0.383 \mathrm{~m})$ 
than for that with $0.40 \mathrm{~m}$ spacing $(0.340 \mathrm{~m})$. However, from location B2 to location B3 (behind two rows of structures), the maximum water surface elevations were reduced by $34.6 \%$ for the array spaced $0.40 \mathrm{~m}$ apart and by $57.4 \%$ for the array spaced $0.20 \mathrm{~m}$ apart. Therefore, while reduced spacing between obstacles may not change the water surface profile drastically for structures near the shoreline, the water surface may reduce more quickly with increasing lines of protection.

Goseberg (2013) identified two macro-roughness parameters to evaluate the change in long-wave run-up based on varied urban configurations: (1) the cross-shore obstruction ratio, $\psi_{c s}$, characterizing the effective obstruction length in the direction of inland propagating flow, and (2) a long-shore obstruction ratio, $\psi_{l s}$, giving the effective width of the macro-roughness. For the configurations tested here, long-shore and cross-shore obstruction ratios and their product (termed "2-D obstruction ratio") are given in Table 5, modified slightly with the note that the experimental configurations tested here did not extend across the entire width of the flume as in the experiments of Goseberg (2013). However, the macro-roughness characterization parameters are still useful. In particular, the 2-D obstruction ratio corroborates the analysis of Figure 12: the configurations with $0.20 \mathrm{~m}$ spacing between elements were characterized by larger 2-D obstruction ratios than configurations with $0.40 \mathrm{~m}$ spacing. Narrower spacing between elements and increased inland distance (larger 2-D obstruction ratios) were thus associated with increased water surface reductions behind additional rows of macro-roughness elements. 
While Goseberg (2013) evaluated the effects of the macro-roughness ratios on reducing run-up, increased 2-D obstruction ratios were also found to change the maximum pressure caused by each wave case. Figure 13 depicts the relationship between $p^{*}$ and $\eta^{*}$ for each spacing and location configuration, and Table 6 lists the percent reduction in pressure for urban roughness configurations, defined as:

$$
P R_{i}=\left(p_{\text {unobstructed }, i}-p_{\text {shielded }, i}\right) / p_{\text {unobstructed, } i} * 100 \%
$$

where $P R_{i}$ indicates the percent reduction in maximum pressure for the shielded specimen in the $i^{\text {th }}$ row with respect to the unobstructed specimen in the nearest setback position.

In the first row, the addition of structural elements did not shield the specimen from impact. However, the reflected wave energy from the obstacle to offshore was affected by adding structures, because additional obstacles reduced the transmission area of the propagating wave. Narrowing the gap between structures is expected to further increase local wave reflection. For rigid obstacles, the reflection and diffraction of waves due to structures may reduce the spatial variation of pressure compared to the single obstacle case. Assuming shoreward structures do not fail, more narrowly spaced configurations may be characterized by greater dissipation of breaking waves in the second and third rows but increased pressure in the first row of structures or in channels due to additional reflected wave energy and flow amplification.

Pressure reductions for shielded specimens were most apparent for breaking wave trials $(\eta *>0.51)$. For nonbreaking waves (Trials 1,2 , and 3), maximum pressures recorded with 
macro-roughness elements were not significantly changed from unobstructed values: the frontal pressure measured when the obstacle was unobstructed or in the first row ranged from $p^{*}=0.67-1.09$, while pressures in the second and third rows were between $p^{*}=0.61$ 1.11. In contrast, Table 6 indicates that after wave breaking occurred $\left(\eta^{*} \geq 0.51\right)$, the maximum pressure exerted by the wave was greatly reduced in the second and third rows. For breaking wave cases, the maximum pressure experienced by a structure positioned behind one or two rows of houses was reduced by as much as 70\% compared to the unobstructed case at the same setback distance. Therefore, direct shielding by shoreward structures can significantly lessen the effects of breaking waves.

Figure 13 and Table 6 also show the effect of varied spacing on pressure, reinforcing the relationship between the 2-D obstruction ratio and reduced tsunami run-up (Goseberg, 2013). Smaller spacing between obstacles effected a larger pressure reduction on directly shielded structures. For example, in the third row, the specimen experiencing a wave with $\eta^{*}=0.83-85$ recorded a $40 \%$ pressure reduction compared to the unobstructed case when obstacles were spaced $0.40 \mathrm{~m}$ apart. Further decreasing the spacing between structures by $0.20 \mathrm{~m}$ caused a pressure reduction by over $70 \%$ for the same wave conditions. More narrowly spaced structures created less space in front of directly shielded structures for turbulent eddies to form, resulting in decreased frontal pressures. However, decreasing the spacing between obstacles increased water velocities in the side streets and maximum pressures on structures in the front row due to reduced flow area and additional reflected wave energy. For this reason, structures not directly shielded from wave propagation may experience larger forces in urban environments (Park et al., 2013). Seawalls that can 
withstand increased wave energy from oblique directions may be useful as a first line of defense against hurricane or tsunami wave forces.

\section{Summary and Conclusions}

\subsection{Model Successes, Limitations and Areas for Future Study}

The experiments presented in this work show the functionality of the Hybrid Tsunami Flume at Ujigawa Laboratory in creating complex wave conditions similar to those observed during the 2011 Tohoku Earthquake Tsunami, characterized by a solitary wave profile superimposed on a longer period water surface rise. Effects of macro-roughness elements in reducing critical pressures on a shielded specimen are also explored. The work here provides insight into important relationships between offshore wave conditions, onshore macro-roughness configurations, and wave-structure interactions; however, experimental limitations and idealizations must be addressed so that future experiments can continue to refine the state-of-the-art in physical modelling of tsunami hydrodynamics.

One limitation of the current experiment is the idealization of the typical Japanese house as a rigid rectangular prism. As discussed above, the specimen was weighted to the bottom with sufficient weight to prevent movement due to the wave impact; thus only horizontal loads are considered in this study. A real tsunami will generate horizontal 
loads as well as vertical loads on the underside of structures; many homes in the inundation region during the 2011 Tohoku Earthquake Tsunami were washed away due to the tsunami wave (Gokon and Koshimura, 2012). Likely, the combination of the horizontal impact force and vertical buoyant forces caused these failures. Further, upon failure, a home will become a threat to shoreward homes due to potential debris impact. Debris impact was not considered in experiments; however strong foundation connections and consideration for uncertainty due to debris loading will be considered in future experiments.

Another consideration is the physical model's ability to represent a prototype tsunami. Comparisons with GPS data obtained from the 2011 Tohoku Earthquake Tsunami indicate that experimental measurements successfully represented the tsunami profiles of GB801 and GB803 (Kawai et al., 2013). However, as Madsen (2008) showed, the short period solitary wave does not accurately represent the time scale of a real-world tsunami. While this work addresses new data that has shown short period waves embedded in a longer-scale water level rise, the mechanically-generated wave still scales to a prototype time shorter than those of real tsunamis. However, tsunami design is regulated by tsunami water level without consideration of the total period and time-dependent load, and video analysis of the Tohoku Earthquake Tsunami showed that the first impact of the tsunami wave on the building's wall could be extremely strong and cause structural failure. Therefore, creating similar maximum wave heights using a combination of wave generation mechanisms marks a step forward in physical modelling of complex realworld events. Future experiments will focus on additional combinations of pump- 
generated flow and mechanically-generated waves to test the facility's ability in generating longer period waves.

Finally, laboratory experiments and numerical models seek to better understand tsunami onshore propagation in order to ultimately design structures to resist tsunami and waveinduced forces. However, design codes that present equations for estimating the maximum force on a structure often must make simplifying assumptions about the maximum tsunami-induced pressure. Therefore, understanding of extreme pressures is an essential starting point for coastal engineers in estimating wave impact loads and the effects of macro-roughness in reducing these loads. Further, extreme pressures must be considered when designing a structure to prevent local damage. Much work has been done to estimate wave-induced forces on structures (e.g. Morison et al., 1950, Ramsden, 1993, Bradner et al., 2009, Fujima et al., 2009, Al-Faesly et al., 2012, Thomas and Cox, 2012, Kihara et al., 2015). While detailed analysis of forces caused by the waves generated in the current experiment and their application to design guidelines is beyond the scope of this work, full integrations of pressure measurements are the subject of current study and will be used to examine the reliability of design equations (e.g. JCO, 2005, ASCE, 2016).

\subsection{Overall Conclusions}


Benchmark experiments indicated that the maximum pressure experienced by structural elements was significantly affected by wave characteristics, wave breaking, and setback distance. Major conclusions from this analysis are threefold:

1. When waves broke on or just before a structure, the maximum pressure recorded on the front face of the specimen more than tripled when compared to that caused by nonbreaking waves. The position of wave breaking itself was affected by the ratio of solitary wave height to total water surface disturbance; this variable, combined with a structure's setback distance from shoreline, can greatly impact the maximum pressure exerted on a structure during a tsunami.

2. As waves approached a pure solitary wave $\left(\eta^{*}=1\right)$, maximum pressures predicted by the tsunami design equation recommended by the Japanese Cabinet Office underestimated measured values when using the bare-earth water surface elevation (Asakura et al., 2000, JCO, 2005). However, estimates were conservative for nonbreaking wave trials, and inputting the total offshore water surface perturbation into the design equation resulted in good agreement between predicted and experimental pressures for breaking wave conditions. Design equations may be conservatively applied in the field and must be further investigated for their application to waves with varying offshore characteristics.

3. The maximum pressure caused by breaking waves decreased by $40-70 \%$ when one or two rows of obstacles shielded the instrumented specimen. If a seaward structure does not fail, design standards may consider conservative reduction factors for structures located behind two or more rows of obstacles when estimating maximum tsunami pressure. 
In practice, a coastal engineer must account for case-specific parameters associated with local bathymetry, community layout, and offshore wave characteristics. Therefore, pressures measured here may not directly apply to structural design criteria for coastal residences. However, in all experiments, critical pressures were generated by breaking waves, and shielding elements consistently reduced the maximum pressure for breaking wave trials. Protective structures that can withstand tsunami wave-induced forces such as breakwaters, seawalls, reinforced dunes, and reinforced concrete buildings (e.g. car parking lot) along the oceanfront are recommended to mitigate damage.

\section{Acknowledgements}

The authors wish to thank all who assisted with experiments and analysis. This material is based upon work supported by the National Science Foundation Graduate Research Fellowship Program (NSF GRFP) under Grant No. 2013115239 and the Hazard Mitigation and Structural Engineering Program under Grant No. 1435007. Any opinions, findings, and conclusions or recommendations expressed in this material are those of the authors and do not necessarily reflect the views of the National Science Foundation. Additional funding was provided by the Japan Society for the Promotion of Science (JSPS) in collaboration with NSF Graduate Research Opportunities Worldwide (GROW) Program (GR14004), and the Disaster Prevention Research Institute (DPRI), Kyoto University. 


\section{References}

Al-Faesly, T., Palermo, D., Nistor, I., and Cornett, A. 2012. Experimental Modeling of Extreme Hydrodynamic Forces on Structural Models. International J. Protective Structures, 3, 4, 477-505.

ASCE. 2016. Minimum design loads for buildings and other structures: Chapter 6 Tsunami Loads and Effects. ASCE/SCI 7-16, New York.

Asakura, R., Iwase, K., and Iketani, T. 2000. Proceedings of the Coastal Eng. of JSCE. 47, 911-915.

Baldock, T.E., Cox, D., Maddux, T., Killian, J., and Fayler, L. 2009. Kinematics of breaking tsunami wave fronts: A data set from large scale laboratory experiments. Coastal Eng.. 2009, 506-516.

Blake, E.S., Kimberlain, T.B., Berg, R.J., Cangialosi, J.P., and Beven, J.L. II. 2013. Tropical Cyclone Report: Hurricane Sandy (AL 182012), 22-29 October 2012. National Hurricane Center. 1-157.

Bradner, C., Schumacher, T., Cox, D., and Higgins, C. 2009. Large scale laboratory measurements of wave forces on highway bridge superstructures. Proceedings of the $31^{\text {st }}$ International Conference, Hamburg, Germany. 3554-3566.

Bremm, G.C., Goseberg, N., Schlurmann, T., and Nistor, I. 2015. Long wave flow interaction with a single square structure on a sloping beach. J. Marine Science and Eng., 3, 821-844. 
Bricker, J.D., Gibson, S., Takagi, H., and Imamura, F. 2015. On the need for larger Manning's roughness coefficients in depth-integrated tsunami inundation models. Coastal Eng. J.. 1-13.

Briggs, M.J., Synolakis, C.E., Harkins, G.S., and Green, D.R. 1995. Laboratory experiments of tsunami runup on a circular island. Pure and Applied Geophysics, 144,3-4, 569-593.

Bullock, G.N., Obhrai, C., Peregrine, D.H., and Bredmose, H. 2007. Violent breaking wave impacts. Part 1: Results from large-scale regular wave tests on vertical and sloping walls. Coastal Eng.. 54, 2007, 602-617.

Chanson, H., Aoki, S.I., and Maruyama, M. 2003. An experimental study of tsunami runup on dry and wet horizontal coastlines. Science of Tsunami Hazards, 20, 5, 278-293.

Chen, C.Y., Hsu, J.R., Chen, H., Kuo, C., and Cheng, M. 2007. Laboratory Observations on internal solitary wave evolution on steep and inverse uniform slopes. Ocean Eng.. 34, 157-17.

Cooker, M.J. and Peregrine, D.H. 1995. Pressure impulse theory for liquid impact problems. J. Fluid Mech. 297, 193-214.

Cooker, M.J. 2002. Liquid impact, kinetic energy loss and compressibility: Lagrangian, Eulerian, and acoustic viewpoints. J. Eng. Mathematics, 44, 259-276.

Cox, D., Tomita, T., Lynett, P., and Holman, R. 2008. Tsunami inundation with macroroughness in the constructed environment. Proceedings of the $31^{\text {st }}$ International Conference on Coastal Eng., 1421-1432. 
Dietrich, J.C., Tanaka, S., Westerink, J.J., Dawson, C.N., Luettich Jr., Zijlema, M., Holthuijsen, L.H., Smith, J.M., Westerink, L.G., and Westerink, H.J. 2012. Performance of the unstructured-mesh, SWAN+ADCIRC model in computing hurricane waves and surge. J. Sci. Comput. 52, 468-497.

Fanelli, C., Fanelli, P., and Wolcott, D. 2013. NOAA water level and meteorological data report: Hurricane Sandy. United States Department of Commerce. Silver Spring, MD.

Fujima, K., Achmad, F., Shigihara, Y., and Mizutani, N. 2009. Estimation of tsunami force acting on rectangular structures. J. Disaster Research, 4, 6, 404-408.

Gokon H. and Koshimura, K. 2012. Mapping of building damage of the 2011 Tohoku Earthquake Tsunami in Miyagi Prefecture. Coastal Eng. J., 54, 1, 1-12.

Goseberg, N., Stahlmann, A., Schimmels, S., and Schlurmann, T. 2008. Highly resolved numerical modelling of tsunami run-up and inundation scenarios in the city of Padang, West Sumatra. Poster proceedings of the International Conference on Coastal Eng., 2008.

Goseberg, N. and Schlurmann, T. 2012. Interaction of idealized urban infrastructure and long waves during run-up and on-land flow process in coastal regions. Proceedings of $33^{\text {rd }}$ Conference on Coastal Eng., Santander, Spain.

Goseberg, N. 2013. Reduction of maximum tsunami run-up due to the interaction with beachfront development- application of single sinusoidal waves. Natural Hazards and Earth System Sciences, 13, 2991-3010.

Goseberg, N., Wurpts, A., and Schlurmann, T. 2013. Laboratory-scale generation of tsunami and long waves, Coastal Eng., 79, 57-74. 
Goto, C. and Shuto, N. 1983. Effects of large obstacles on tsunami inundations, in: Tsunamis: Their Science and Engineering, edited by Iida, K. and Iwasaki, T. chap. Tsunami Run-up, 515-525, Terra Science Pub. Co., Tokyo/Reidel, Dordrecht.

Hattori, M., Arami, A., and Yui, T. 1994. Wave impact pressure on vertical walls under breaking waves of various types. Coastal Eng., 22, 1-2, 779-114.

Holthuijsen, L.H., Booij, N., and Ris, R.C. 1993. A spectral wave model for the coastal zone. Proceedings $2^{\text {nd }}$ International Symposium on Ocean Wave Measurement and Analysis, New Orleans, Louisiana, July 23-28, 1993, New York, 630-641.

Irish, J., Weiss, R., Yang, Y., Song, Y.K., Zainali, A., Marivela-Colmenarejo, R. 2014. Laboratory experiments of tsunami run-up and withdrawal in patchy coastal forest on a steep beach. Nat Hazards, 74, 1933-1949.

JCO/Task Committee under the Japanese Cabinet Office. 2005. Design Guidelines for Tsunami Shelters (in Japanese), http://www.bousai.go.jp/oshirase/h17/ tsunami_s iryo 2.pdf

JCO: Japanese Cabinet Office. 2011. Off the Pacific Ocean Earthquake and Resulting Tsunamis: Chapter III- Disaster Damage in Japan from the Tohoku District. Prime Minister's Official Residence, III-1-III-23.

Jelesnianski, C.P., Chen, J., and Shaffer, A. 1992. SLOSH: Sea, lake, and overland surges from hurricanes. NOAA Technical Report NWS 48, National Oceanic and Atmospheric Administration, US Department of Commerce, 1-71.

Kawai, H., Satoh, M., Kawaguchi, K., and Seki, K. 2012. Recent tsunamis observed by GPS buoys off the Pacific coast of Japan. Coastal Eng. Proceedings, 33, 1-15. 
Kawai, H., Satoh, M., Kawaguchi, K., and Seki, K. 2013. Characteristics of the 2011 Tohoku Tsunami waveform acquired around Japan by NOWPHAS Equipment. Coastal Eng. J., 55, 4, 1350008.

Kazama, M., and Noda, T. 2012. Damage Statistics (Summary of the 2011 off the Pacific Coast of Tohoku Earthquake damage). Soils and Foundations, 52, 5, 780-792.

Kihara, N., Niida, Y., Takabatake, D., Kaida, H., Shibayama, A., and Miyagawa, Y. 2015. Large-scale experiments on tsunami-induced pressure on a vertical tide wall, Coastal Eng., 99, 46-63.

Koshimura, S., Oie, T., Yanagisawa, H., and Imamura, F. 2009. Developing fragility functions for tsunami damage estimation using numerical model and post-tsunami data from Banda Aceh, Indonesia. Coastal Eng. J., 51, 3, 243-273.

Lackey, M., National Climactic Data Center. 2011. Billion Dollar US/Climate Disasters [Data File]. Retrieved from http://www.ncdc.noaa.gov/img/reports/billion/ disasters2010.pdf.

Leone, F., Lavigne, F., Paris, R., Denain, J.C., and Vinet, F. 2011. A spatial analysis of the December 26th, 2004 tsunami-induced damages: Lessons learned for a better risk assessment integrating buildings vulnerability. Applied Geography, 31, 1, 363375.

Liu, P.L.F., Cho, Y.S., Briggs, M.J., Kanoglu, U., Synolakis, C.E. 1995. Runup of solitary waves on a circular island. J. Fluid Mechanics, 302, 1, 259-285.

Luettich, R.A., Jr., Westerink, J.J., and Scheffner, N.W. 1992. ADCIRC: an advanced three-dimensional circulation model for shelves coasts and estuaries, report 1: theory and methodology of ADCIRC-2DDI and ADCIRC-3DL. Dredging 
Research Program Technical Report DRP-92-6, US Army Engineers Waterways Experiment Station, Vicksburg, MS, 1-137.

Lynett, P., Wu, T., and Liu, P. 2002. Modeling wave runup with depth-integrated equations. Coastal Eng., 46, 89-107.

Lynett, P., Liu, P., Sitanggang, K., and Kim, D. 2008. Modeling wave generation, evolution, and interaction with depth-integrated, dispersive wave equations. COULWAVE Code Manual. Cornell University Long and Intermediate Wave Modeling Package. 2.0. 1-90.

Ma, G., Shi, F., and Kirby, J.T. 2012. Shock-capturing non-hydrostatic model for fully dispersive surface wave processes. Ocean Modelling, 43-44, 22-35.

Madsen, P.A., Fuhrman, D.R., and Schaffer, H.A. 2008. On the solitary wave paradigm for tsunamis, J. Geophys. Research, 113, C12012, doi 10.1029/2008JC004932.

McLachlan, A. and Dorvlo, A. 2005. Global patterns in sandy beach microbenthic communities. J. Coastal Research, 21, 4, 674-687.

Mimura, N., Yasuhara, K., Kawagoe, S., Yokoki, H., and Kazama, S. 2011. Damage from the Great East Japan Earthquake and Tsunami- A quick report. Mitigation and Adaptation Strategies for Global Change. 16, 7, 803-818.

Mori, N., Takahashi, T, Yasuda, T., and Yanagisawa, H. 2011. Survey of 2011 Tohoku earthquake tsunami inundation and run-up. Geophysical research letters, 38 (7). L00G14.

Mori, N. and Takahashi, T. 2012. Nationwide post event survey and analysis of the 2011 Tohoku Earthquake Tsunami. Coastal Eng. J., 54, 1, 1250001. 
Mori, N., Kato, M., Kim, S., Mase, H., Shibutani, Y., Takemi, T., Tsuboki, K., and Yasuda, T. 2014. Local amplification of storm surge by Super Typhoon Haiyan in Leyte Gulf. Geophysical Research Letters. 41, 14, 5106-5113.

Morison, J.R., O’Brien, M.P., Johnson, J.W., and Schaaf, S.A. 1950. The Forces Exerted by Surface Waves on Piles. Petrol Trans.189, 149-157.

Nandasena, N.A.K., Sasaki, Y., and Tanaka, N. 2012. Modeling field observations of the 2011 Great East Japan Tsunami: Efficacy of artificial and natural structures on tsunami mitigation. Coastal Eng., 67, 1-13.

NOWPHAS: Nationwide Ocean Wave information for Ports and HArbourS. Tohoku Earthquake Tsunami GPS Buoy Data. 11 March 2011. Port and Airport Research Institute (PARI). Yokosuka, Japan.

Nicholls, R.J. and Small, C. 2002. Improved estimates of coastal population and exposure to hazards released, Eos Trans. AGU, 83, 28, 301-305.

ODOT: Oregon Department of Transportation. 2014. Appendix A- Hydraulic roughness (Manning's n) Values of Conduits and Channels. ODOT Hydraulics Manual, Salem, OR.

Oshnack, M.E., Aguiniga, F., Cox, D., Gupta, R., and van de Lindt, J. 2009. Effectiveness of small onshore seawalls in reducing forces induced by Tsunami bore: Large scale experimental study. J. Disaster Res., 4 (6) , 382-390.

Oumeraci, H., Klammer, P., and Partenscky, H.W. 1993. Classification of breaking wave loads on vertical structures. J. Waterway, Port, Coastal, and Ocean Eng.. 1194 , 381-397. 
Papadopoulos, G.A., Caputo, R., McAdoo, B., Pavlides, S., Karasthis, V., Fokaefs, A., Orfanogiannaki, K., and Valkaniotis, S. 2006. The large tsunami of 26 December 2004: Field observations and eyewitnesses accounts from Sri Lanka, Maldives Is. and Thailand. Earth Planets and Space, 58, 2, 233-241.

Park, H., Cox, D.T., Lynett, P.J., Wiebe, D.M., Shin, S. 2013. Tsunami inundation modeling in constructed environments: A physical and numerical comparison of free-surface elevation, velocity, and momentum flux. Coastal Eng., 79, 2,. 9-21.

Peregrine, D.H. 2003. Water wave impacts on walls. Annual Rev. Fluid Mech. 35, 23-43.

Ramsden, J.D. 1993. Tsunamis: Forces on a vertical wall caused by long waves, bores, and surges on a dry bed. PhD Thesis, California Institute of Technology, Pasadena, California.

Reis, A. H. and Gama, C. 2010. Sand size versus beachface slope- An explanation based on the Constructal Law. Geomorphology, 114, 276-283.

Robertson, I.N. Riggs, H.R., Yim, S.C., and Young, Y.L. 2007. Lessons from Hurricane Katrina storm surge on bridges and buildings. J. Waterway, Port, Coastal, and Ocean Eng.-ASCE, 133, 463-483.

Rossetto, T., Allsop, W., Charvet, I., and Robinson, D.I. 2011. Physical modelling of tsunami using a new pneumatic wave generator. Coastal Eng., 58, 6, 517-527.

Small, C. and Nicholls, R.J. 2003. A global analysis of human settlement in coastal zones. J. Coastal Research, 19, 3, 584-599. 
Suppasri, A., Mas, E., Koshimura, S., and Imai, K. 2012. Developing tsunami fragility curves from the surveyed data of the 2011 Great East Japan Tsunami in Sendai and Ishinomaki Plains. Coastal Eng. J., 54, 1-16.

Suppasri, A., Shuto, N., Imamura, F., Koshimura, S., Mas, E., and Yalciner, A.C. 2013a. Lessons learned from the 2011 Great East Japan Tsunami: Performance of tsunami countermeasures, coastal buildings, and tsunami evacuation in Japan. Pure Appl. Geophys, 170, 2013, 993-1018.

Suppasri, A., Mas, E., Charvet, I., Gunasekera, R., Imai, K., Fukutani, Y., Abe, Y., and Imamura, F. 2013b. Building damage characteristics based on surveyed data and fragility curves of the 2011 Great East Japan tsunami. Nat. Hazards, 66, 319-341.

Synolakis, C.E. 1987. The runup of solitary waves. J. Fluid Mechanics, 185, 523-545.

Tajima, Y., Yasuda, T., Pacheco, B.M., Cruz, E.C., Kawasaki, K., Nobuoka, H., Miyamoto, M., Asano, Y., Arikawa, T., and Ortigas, N.M. 2014. Initial report of JSCE-PICE joint survey on the storm surge disaster caused by Typhoon Haiyan. Coastal Eng. J., 56, 1, 1450006.

Thomas, S. and Cox, D. 2012. Influence of finite-length seawalls for tsunami loading on coastal structures. J. Waterway, Port, Coastal, and Ocean Eng., 138, 3, 203-214.

Thomas, S., Killian, J., and Bridges, K. 2015. Influence of macroroughness on tsunami loading of coastal structures. J. Waterway, Port, Coastal, and Ocean Eng., 141, 1.

Tomiczek, T., Kennedy, A., and Rogers, S., 2014. Collapse limit state fragilities of woodframed residences from storm surge and waves during Hurricane Ike.” J. Waterway, Port, Coastal, and Ocean Eng., 140, 1, 43-55. 
Tomiczek, T., Kennedy, A., Zhang, Y., Owensby, M., Hope, M.E., Lin, N., and Flory, A., 2016. Hurricane damage classification methodology and fragility functions derived from Hurricane Sandy's effects in coastal New Jersey. J. Waterway, Port, Coastal, and Ocean Eng., resubmitted.

Tomita, T., Honda, K., and Kakinuma, T. 2006. Application of three-dimensional tsunami simulator to estimation of tsunami behavior around structures, Int. Conf. on Coastal Eng., San Diego.

Tomita, T. and Honda, K. 2009. Tsunami estimation including effect of coastal structures and buildings by 3D model. Coastal Structures ' 07 .

Tsuji, Y., Namegaya, Y., Matsumoto, H., Iwasaki, S.I., Kanuba, W., Sriwachai, M., and Meesuk, V. 2006. The 2004 Indian tsunami in Thailand: Surveyed runup heights and tide gauge records. Earth Planets and Space, 58, 2, 223-232.

Udo, K., Sugawara, D., Tanaka, H., Imai, K., and Mano, A. 2012. Impact of the 2011 Tohoku Earthquake and Tsunami on beach morphology along the Northern Sendai Coast. Coastal Eng. J., 54,1, 1250009.

van de Lindt, J.W., Graettinger, A., Gupta, R., Skaggs, T., Pryor, S., and Fridley, K.J. 2007. Performance of wood-frame structures during Hurricane Katrina. J. Performance of Constructed Facilities, 21, 2, 108-116.

van de Lindt, Gupta, R., Garcia, R.A., and Wilson, J. 2009. Tsunami bore forces on a compliant residential building model. Eng. Structures, 31, 2, 2534-2539.

Wei, G. and Kirby, J.T. 1995. A time-dependent numerical code for extended Boussinesq equations. J. Waterway, Port, Coastal, and Ocean Eng., 120, 251-261. 
Westerink, J.J., Luettich, R.A., Feyen, J.C., Atkinson, J.H., Dawson, C., Roberts, H., Powell, M.D., Dunion, J.P., Kubatko, E.J., and Pourtaheri, H. 2008. A Basin- To Channel-Scale Unstructured Grid Hurricane Storm Surge Model Applied To Southern Louisiana. Monthly Weather Review, 136, 3, 833-864.

Wood, D.J., Peregrine, D.H., and Bruce, T. 2000. Wave impact on a wall using pressureimpulse theory. I: Trapped Air. J. Waterway, Port, Coastal, and Ocean Eng., 2000, $126,4,182-190$.

Yeh, H. 2009. Tsunami impacts on coastlines. The Sea: Tsunamis. Ed. Eddie N. Bernard, Allan R. Robinson. Cambridge: Harvard University Press, 2009. 333-370. 


\section{Tables}

Table 1: Wave gauge positions (distance in meters from the origin of the mechanical paddle).

\begin{tabular}{|c|c|c|c|c|c|c|c|c|}
\hline Config. & $\mathbf{L}(\mathbf{m})$ & $\mathbf{x}_{\text {box }}(\mathbf{m})$ & WG5 & WG6 & WG7 & WG8 & WG9 & WG10 \\
\hline 1 & 0.79 & 22.79 & 21.50 & 22.69 & 24.89 & 22.99 & 23.29 & 24.09 \\
\hline 2 & 1.59 & 23.59 & 21.50 & 22.69 & 24.89 & 23.79 & 23.49 & 24.09 \\
\hline 3 & 2.39 & 24.39 & 21.50 & 22.69 & 24.89 & 24.59 & 23.49 & 24.29 \\
\hline 4 & $\begin{array}{c}\text { Front, } \\
\mathrm{a}=20 \mathrm{~cm}\end{array}$ & 22.79 & 21.50 & $\mathrm{n} / \mathrm{a}$ & 22.69 & 22.99 & 23.29 & 23.89 \\
\hline 5 & $\begin{array}{l}\text { Middle, } \\
\mathrm{a}=20 \mathrm{~cm}\end{array}$ & 23.39 & 21.50 & 22.69 & 23.29 & 23.49 & 22.99 & 23.49 \\
\hline 6 & $\begin{array}{c}\text { Rear, } \\
a=20 \mathrm{~cm}\end{array}$ & 23.99 & 21.50 & 22.69 & 23.29 & 24.19 & 23.89 & 24.49 \\
\hline 7 & $\begin{array}{l}\text { Front, } \\
\mathrm{a}=40 \mathrm{~cm}\end{array}$ & 22.79 & 21.50 & $\mathrm{n} / \mathrm{a}$ & 22.69 & 22.99 & 23.29 & 24.19 \\
\hline 8 & $\begin{array}{l}\text { Middle, } \\
\mathrm{a}=40 \mathrm{~cm}\end{array}$ & 23.59 & 21.50 & 22.69 & 23.29 & 23.79 & 22.99 & 23.79 \\
\hline 9 & $\begin{array}{c}\text { Rear, } \\
a=40 \mathrm{~cm}\end{array}$ & 24.39 & 21.50 & 22.69 & 24.89 & 24.59 & 23.29 & 24.29 \\
\hline
\end{tabular}

Table 2: Summary of initial conditions and offshore water surface elevations at $x=14.50$ $\mathrm{m}$. Experiments were run for each of the nine setback and spacing configurations. Mechanical waves were generated after 60 seconds of pump flow.

\begin{tabular}{|c|cccc} 
Trial & $\begin{array}{c}\text { Mechanical } \\
\text { Input }(\mathbf{m})\end{array}$ & $\begin{array}{c}\text { Pump Input } \\
\mathbf{3}\end{array}$ & $\begin{array}{c}\left(\mathbf{\eta}_{\text {wave }}^{-}+\boldsymbol{\eta}_{\text {flow }}\right. \\
\mathbf{x = 1 4 . 5 0} \mathbf{~ m}\end{array}$ & $\begin{array}{c}\text { Standard } \\
\text { deviation }(\mathbf{c m})\end{array}$ \\
\hline 1 & 0 & 0.80 & 43.19 & 1.72 \\
2 & 0.10 & 0.60 & 43.08 & 1.33 \\
3 & 0.15 & 0.40 & 40.74 & 0.71 \\
4 & 0.20 & 0.30 & 40.76 & 0.41 \\
5 & 0.25 & 0.20 & 39.63 & 0.15 \\
6 & 0.35 & 0.10 & 41.94 & 0.15 \\
7 & 0.40 & 0.10 & 47.71 & 0.18
\end{tabular}


Table 3: GPS buoy locations and wave characteristics during the March 11, 2011 Tohoku Earthquake Tsunami.

\begin{tabular}{|c|cccccc} 
WG & $\boldsymbol{\eta}^{*}$ & $\mathbf{t}^{*}$ & Latitude $\left({ }^{\circ} \mathbf{N}\right)$ & Longitude $\left({ }^{\circ} \mathbf{W}\right)$ & Location & Depth $(\mathbf{m})$ \\
\hline GB807 & 0.897 & 0.486 & 40.117 & 142.067 & N. Iwate & 125 \\
GB804 & 0.784 & 0.604 & 39.627 & 142.187 & C. Iwate & 200 \\
GB802 & 0.660 & 0.682 & 39.259 & 142.097 & S. Iwate & 204 \\
GB803 & 0.379 & 0.834 & 38.858 & 141.894 & N. Miyagi & 160 \\
GB801 & 0.179 & 0.905 & 38.233 & 141.684 & C. Miyagi & 144 \\
GB806 & 0.619 & 0.588 & 36.971 & 141.186 & Fukushima & 137
\end{tabular}

Table 4: Vertical locations of maximum pressure recordings on the front face of the structure. Bolded cells indicate the first trial in which waves broke on the specimen.

\begin{tabular}{|c|c|c|c|}
\hline Trial & $0.79 \mathrm{~m}$ & $1.59 \mathrm{~m}$ & $2.39 \mathrm{~m}$ \\
\hline 1 & $\mathrm{z}=0.01$ & $\mathrm{z}=0.01$ & $\mathrm{z}=0.01$ \\
\hline 2 & $\mathrm{z}=0.01$ & $\mathrm{z}=0.01$ & $\mathrm{z}=0.01$ \\
\hline 3 & $\mathrm{z}=0.01$ & $\mathrm{z}=0.01$ & $\mathrm{z}=0.05$ \\
\hline 4 & $\mathrm{z}=0.05$ & $\mathrm{z}=\mathbf{0 . 1 5}$ & $\mathrm{z}=\mathbf{0 . 1 5}$ \\
\hline 5 & $\mathrm{Z}=\mathbf{0 . 0 5}$ & $\mathrm{z}=0.15$ & $\mathrm{z}=0.05$ \\
\hline 6 & $\mathrm{z}=0.01$ & $\mathrm{z}=0.01$ & $\mathrm{z}=0.01$ \\
\hline 7 & $\mathrm{z}=0.05$ & $\mathrm{z}=0.05$ & $\mathrm{z}=0.05$ \\
\hline
\end{tabular}

Table 5: Cross-shore, long-shore, and 2-D obstruction ratios defined by Goseberg (2012) for experimental configurations.

\begin{tabular}{|l|cc|cc|}
\hline & \multicolumn{2}{|c|}{$\mathbf{0 . 4 0} \mathbf{~ m}\left(\boldsymbol{\psi}_{\mathrm{ls}}=\mathbf{0 . 5}\right)$} & \multicolumn{2}{c|}{$\mathbf{0 . 2 0} \mathbf{~ m}\left(\boldsymbol{\psi}_{\mathrm{ls}}=\mathbf{0 . 6 7}\right)$} \\
& $\boldsymbol{\psi}_{\mathrm{cs}}$ & $\boldsymbol{\psi}_{\mathrm{cs}} \boldsymbol{\psi}_{\mathrm{ls}}$ & $\boldsymbol{\psi}_{\mathrm{cs}}$ & $\boldsymbol{\psi}_{\mathrm{cs}}=\boldsymbol{\psi}_{\mathrm{ls}}$ \\
\hline 1 row shield & 1.0 & 0.5 & 1.0 & 0.67 \\
2 row shield & 1.5 & 0.75 & 1.25 & 0.83 \\
3 row shield & 1.67 & 0.83 & 1.33 & 0.89 \\
\hline
\end{tabular}

Table 6: Percent reduction of maximum pressure experienced by shielded specimen, compared to unobstructed cases at nearest setback distances. Bolded values of $\mathrm{p}^{*}$ indicate the first case of wave breaking for each setback distance. 


\begin{tabular}{|c|c|c|c|c|c|c|c|}
\hline$\eta *$ & 0.00 & 0.27 & 0.40 & 0.51 & 0.64 & $\mathbf{0 . 8 3}$ & 0.85 \\
\hline $\mathrm{p}^{*}\left(\mathbf{L}_{1}=0.79 \mathrm{~m}\right)$ & 0.87 & 0.98 & 1.04 & 1.36 & 4.52 & 4.17 & 3.34 \\
\hline $\mathrm{PR}_{1}, \mathrm{a}=20 \mathrm{~cm}, \%$ & 7.11 & -0.19 & -5.25 & -6.54 & 28.34 & 2.20 & -50.85 \\
\hline$P R_{1}, a=40 \mathrm{~cm}, \%$ & 23.54 & 32.25 & -1.51 & 4.90 & 30.75 & -10.54 & -39.51 \\
\hline $\mathrm{p}^{*}\left(\mathrm{~L}_{2}=1.59 \mathrm{~m}\right)$ & 0.86 & 0.90 & 0.94 & 3.77 & 2.27 & 4.11 & 3.61 \\
\hline $\mathrm{PR}_{2}, \mathrm{a}=20 \mathrm{~cm}, \%$ & 28.42 & 20.77 & 3.14 & 69.02 & 45.17 & 68.47 & 70.02 \\
\hline $\mathrm{PR}_{2}, \mathrm{a}=40 \mathrm{~cm}, \%$ & 26.36 & 12.60 & 17.72 & 51.96 & 33.52 & 67.69 & 53.35 \\
\hline $\mathrm{p}^{*}\left(\mathrm{~L}_{3}=2.39 \mathrm{~m}\right)$ & 0.83 & 0.94 & 1.08 & 2.17 & 1.95 & 3.41 & 2.95 \\
\hline $\mathrm{PR}_{3}, \mathrm{a}=20 \mathrm{~cm}, \%$ & 19.93 & 36.13 & 23.96 & 57.66 & 52.73 & 72.44 & 71.28 \\
\hline $\mathrm{PR}_{3}, \mathrm{a}=40 \mathrm{~cm}, \%$ & 12.34 & 19.15 & 4.64 & 45.19 & 28.25 & 44.40 & 39.34 \\
\hline
\end{tabular}




\section{Figure Captions}

Figure 1: (a) Plan and (b) profile views of experimental flume and wave gauge positions, with onshore locations as in Configuration 1. All dimensions are in meters.

Figure 2: Schematic of the front, lateral, and rear faces of the instrumented specimen, showing locations of pressure gauges. All dimensions are in meters.

Figure 3: Photographs of wave flume and instrumentation. Left: resistance wave gauges and ADVs positioned in hydraulic wave flume. Right: instrumented specimen and frontside pressure gauges, wave gauge, and ADV.

Figure 4: Pressure time series for Trial 7, Configuration 3, on the front (blue line), lateral (red line), and rear (black line) pressure sensors, mounted along the structure's centerline at elevation $\mathrm{z}=0.01 \mathrm{~m}$. Inset: location of depicted pressure time series on the front, lateral, and rear sides. Time is measured from onset of pumping flow.

Figure 5: Unobstructed structural element configurations with associated wave gauges and ADV locations: (a) Configuration 1, (b) Configuration 2, and (c) Configuration 3.

Figure 6: Experimental configurations with macro-roughness elements. (a, b, and c) Configurations 4, 5, and 6 (0.20 m spacing); (d, e, and f) Configurations 7, 8, and 9 (0.40 $\mathrm{m}$ spacing). Instrumented specimen is designated with a star for each configuration. The $\mathrm{x}$-distances of wave gauges from the mechanical paddle are given in Table 1. Front and rear ADVs and wave gauges were positioned $0.10 \mathrm{~m}$ from the face of the instrumented structural element and at the midpoint between non-instrumented obstacles. Lateral ADVs were positioned $0.15 \mathrm{~m}$ behind the leading edge and $0.10 \mathrm{~m}$ to the side of the nearest structural element; lateral wave gauges were positioned $0.10 \mathrm{~m}$ behind the leading edge and $0.20 \mathrm{~m}$ to the side of the structural element.

Figure 7: Water surface time series for WGs 1-5 for each of the seven combinations of pumping flow rates and mechanical wave target inputs listed in Table 2. Time is measured from the initiation of pump flow.

Figure 8: Water surface elevation vs. local time and methodology for calculating $\mathrm{t}^{*}$ and $\eta^{*}$ using NOWPHAS (2011) wave gauge data. Slow rise time $t_{\text {slow }}$ is shown in red over the blue water surface elevation time series.

Figure 9: Relationship between $t^{*}$ and $\eta^{*}$ for flume $W G$ data and tsunami profiles obtained by GPS Buoys after the 2011 Tohoku Earthquake Tsunami.

Figure 10: Maximum front pressure, nondimensionalized by (a) total offshore water surface perturbation $\left(\eta_{\text {wave }}+\eta_{\text {flow }}\right)$ and (b) local bare-earth water surface elevation $\left(\eta_{\text {be }}\right)$ vs. offshore solitary wave fraction, unobstructed configurations. Setback distances are 
$\mathrm{L}_{1}=0.79 \mathrm{~m}$ (blue, bold line), $\mathrm{L}_{2}=1.59 \mathrm{~m}$ (red, thin line), $\mathrm{L}_{3}=2.39 \mathrm{~m}$ (black, dotted line). Note the differences in y-axis scale.

Figure 11: Effects of setback distance and wave characteristics on maximum pressure: dimensionless pressure vs. nondimensional setback distance for each configuration, for the $\eta^{*}$ conditions of Trials 1-7. Stars indicate conditions in which wave breaking occurred on or just before the structure $\left[(2.00,4.52)\left(\eta^{*}=0.64\right)\right.$ and $(3.93,3.77)$ $(\eta *=0.51)]$.

Figure 12: Urban roughness effects on maximum water surface elevation for Trials 1-7 of Table 2. Locations (B1-B4) correspond with beach positions shown in Figures 5 and 6. Blue line: $20 \mathrm{~cm}$ spaced array; black line: $40 \mathrm{~cm}$ spaced array; red line: unobstructed obstacle positioned $0.79 \mathrm{~m}$ from shore.

Figure 13: Urban roughness effects on maximum pressure. Maximum pressure vs. solitary wave ratio: (a): front row; (b): $1.59 \mathrm{~m}$ setback or in second line of houses; (c): $2.39 \mathrm{~m}$ setback or in third line of houses. Blue lines (exes) indicate unobstructed case at appropriate location; red lines (squares) and black lines (circles) indicate $0.20 \mathrm{~m}$ and 0.40 $\mathrm{m}$ spacing between structures, respectively. 


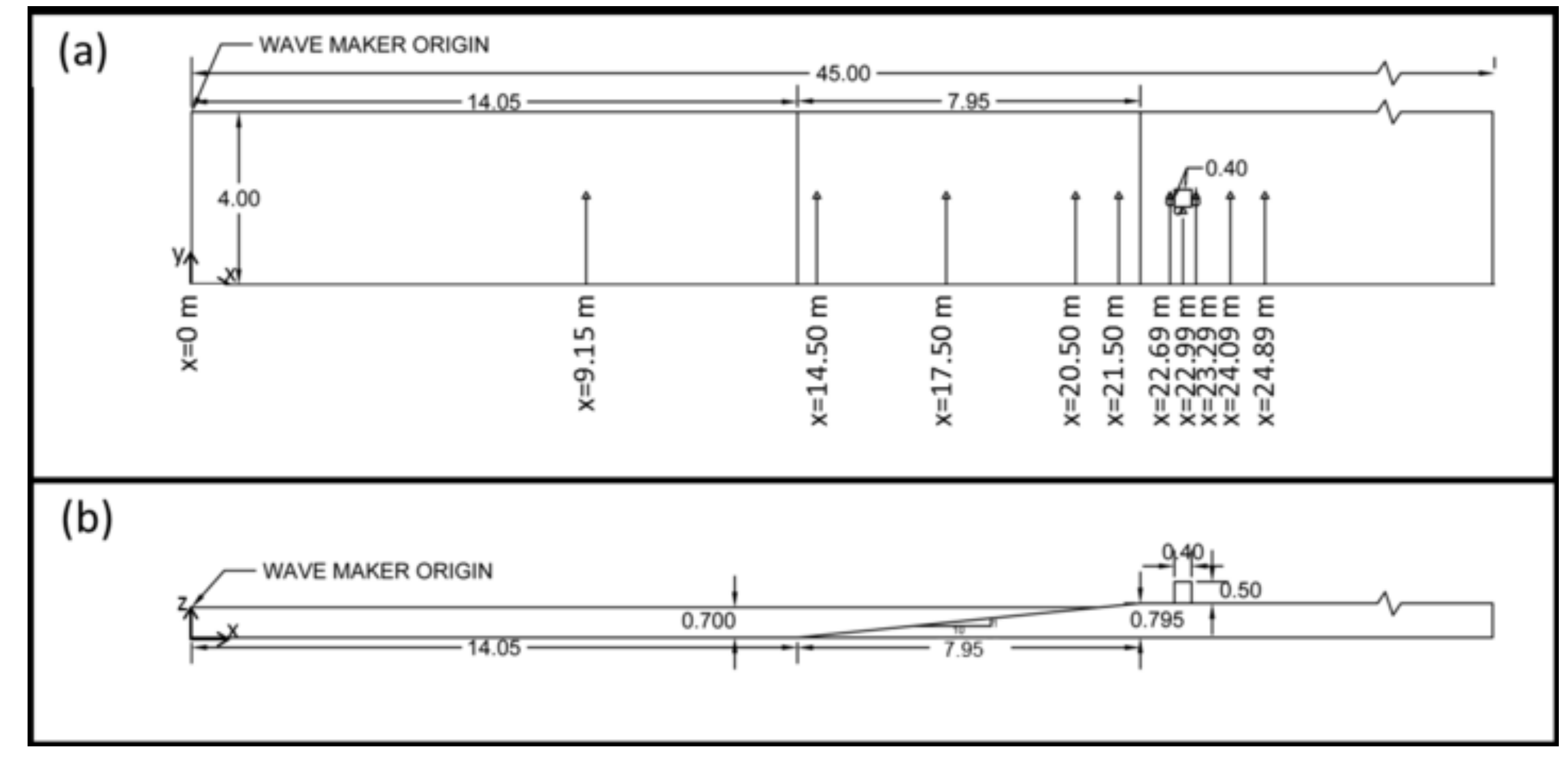

(b)

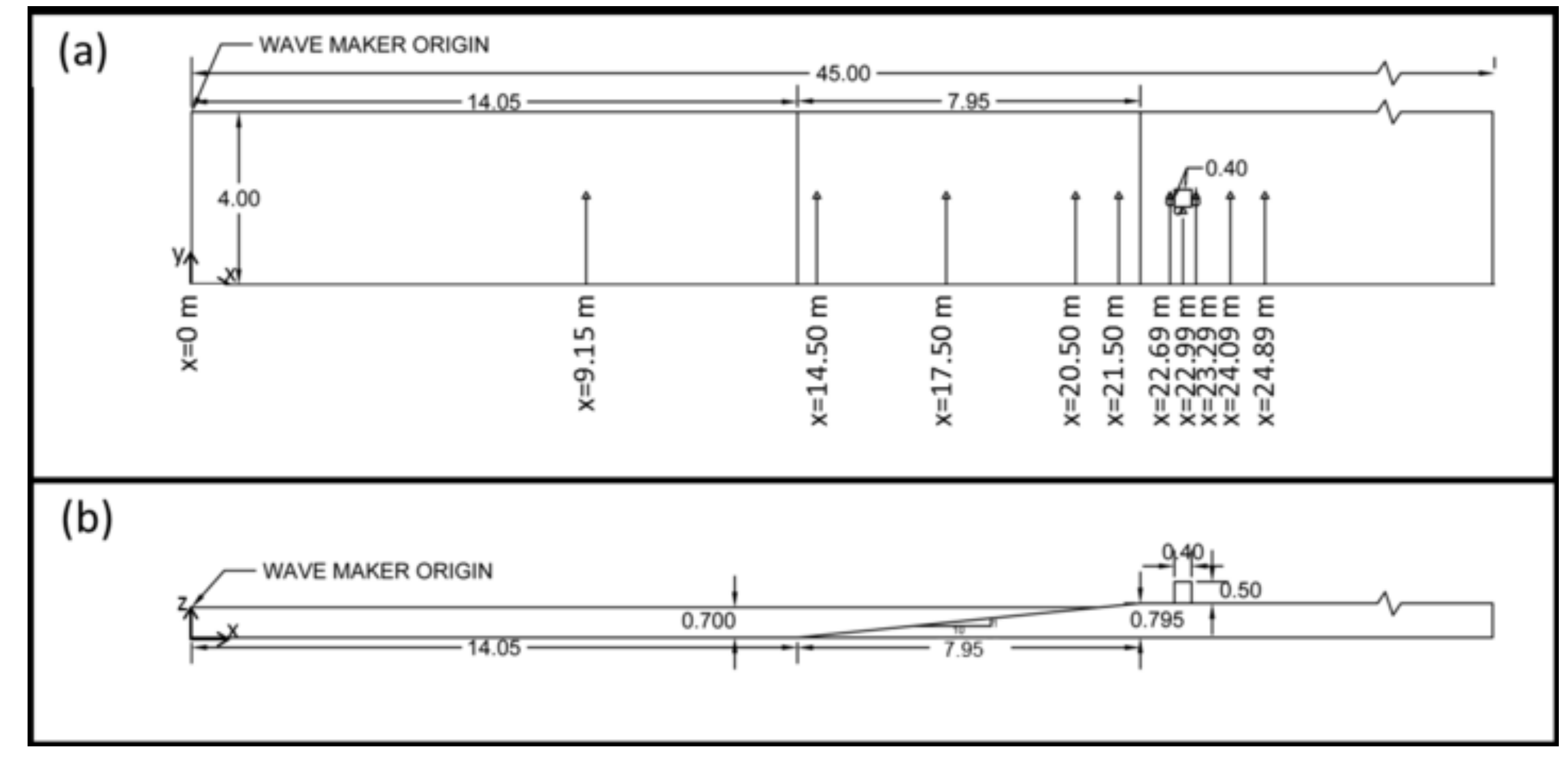


Figure 2

FRONT

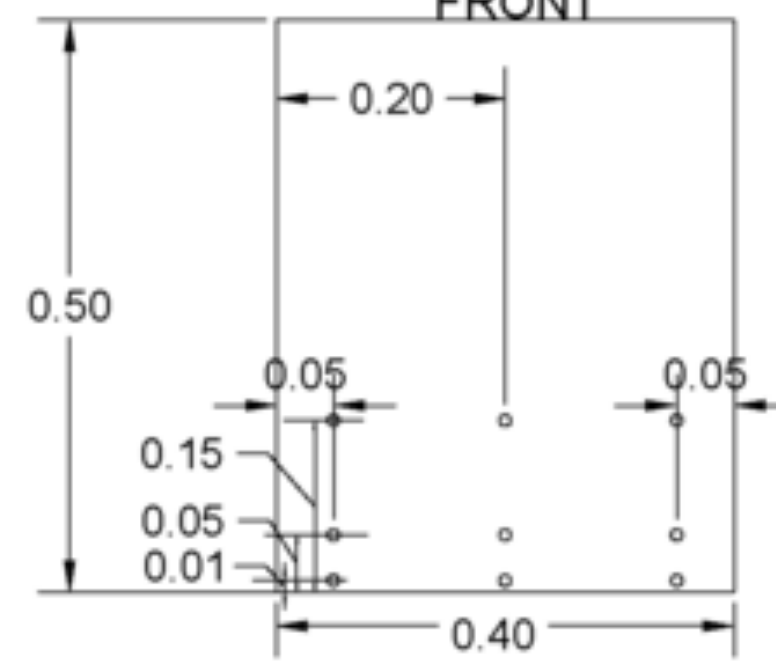

LATERAL

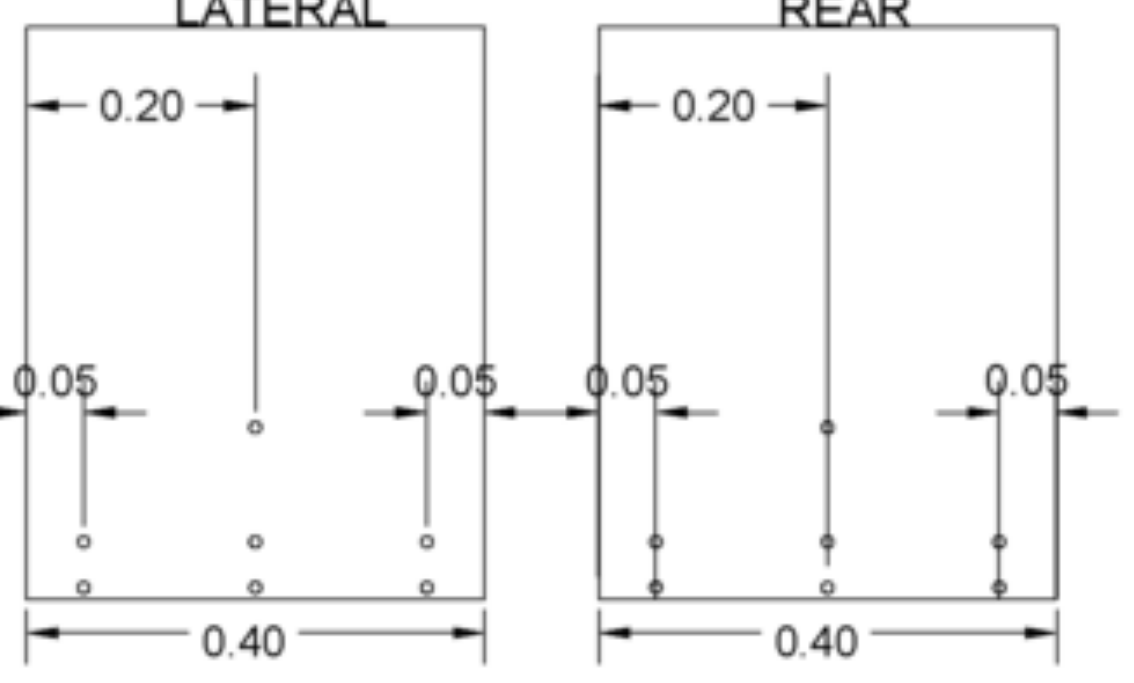




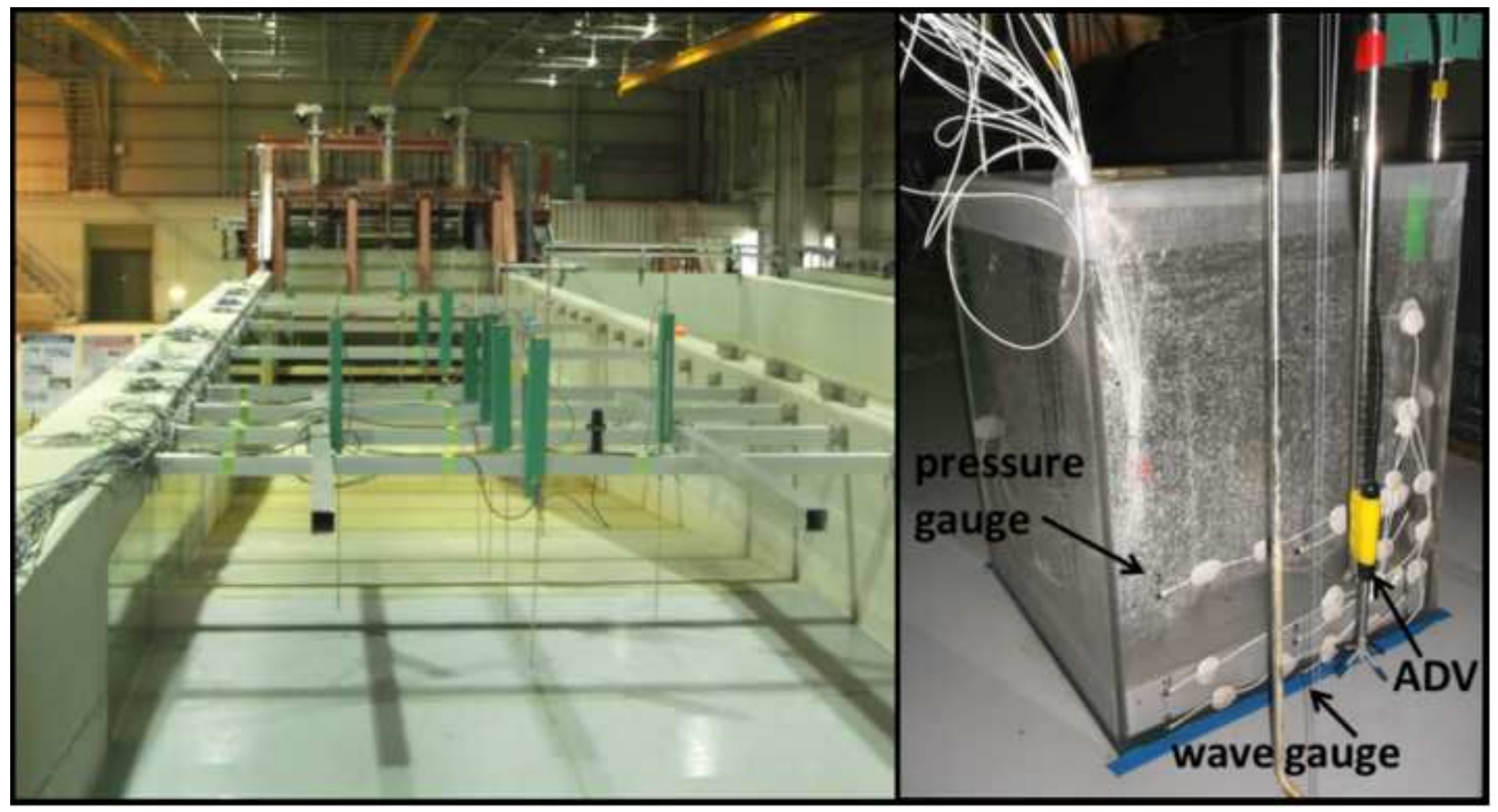




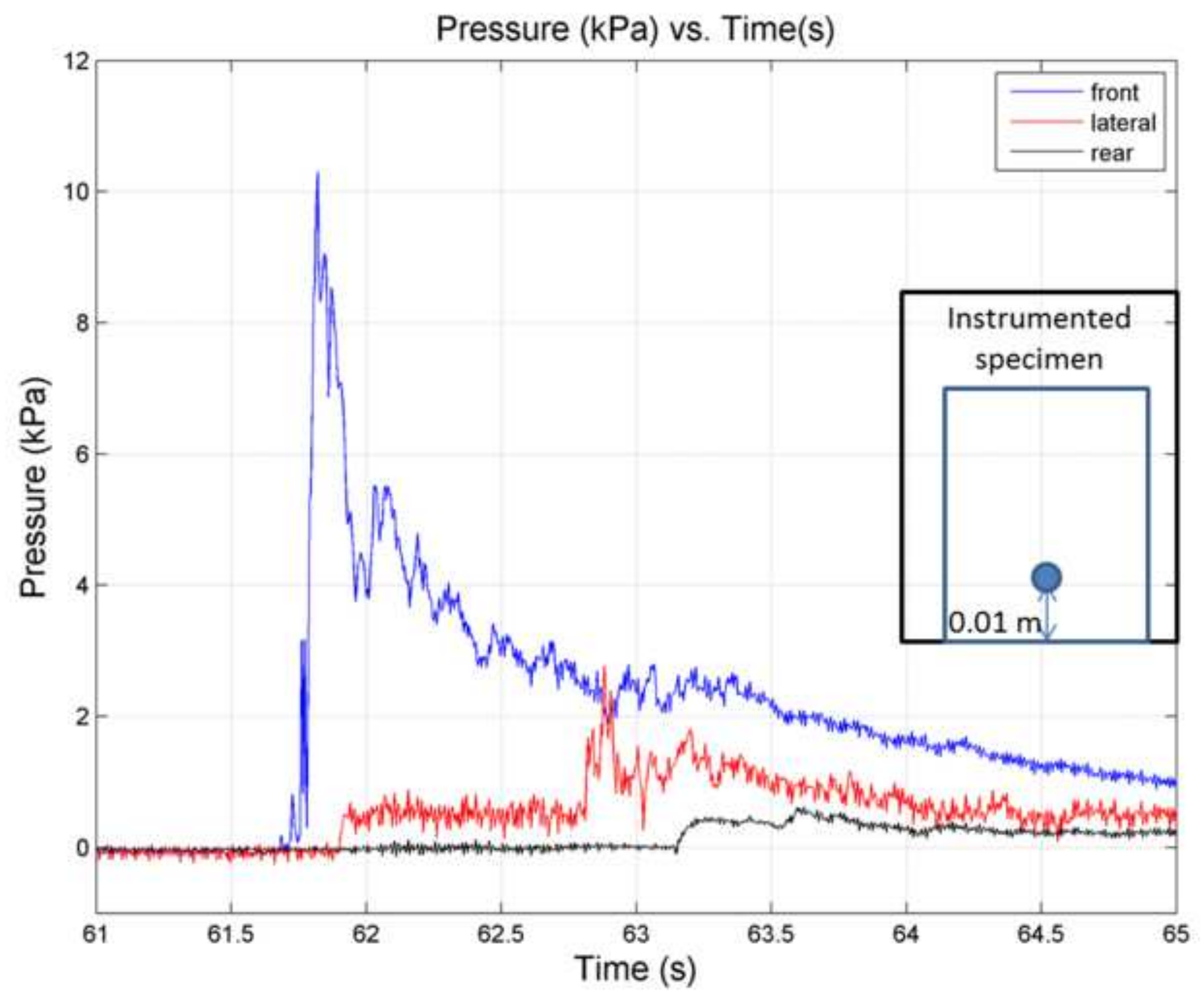




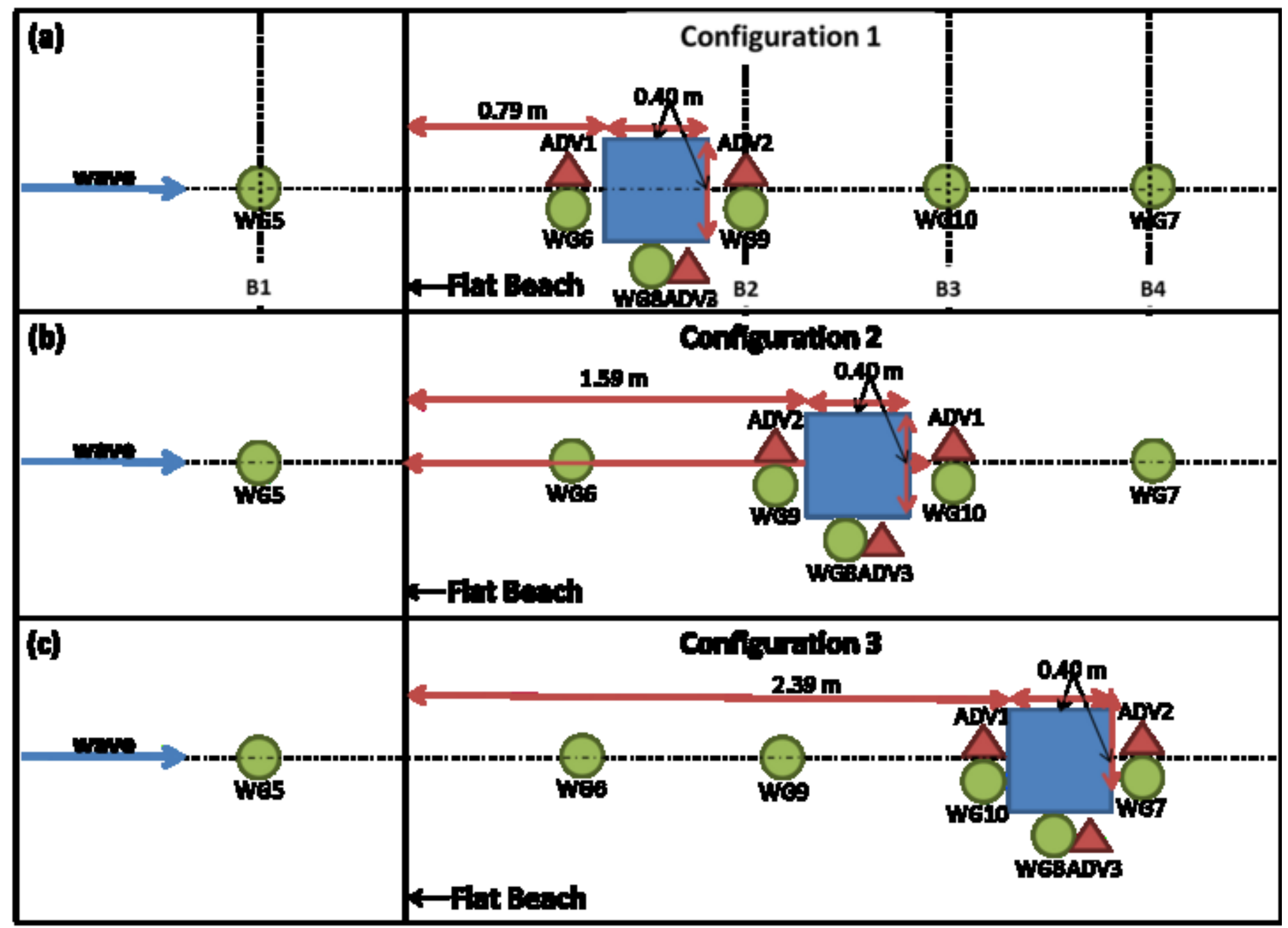




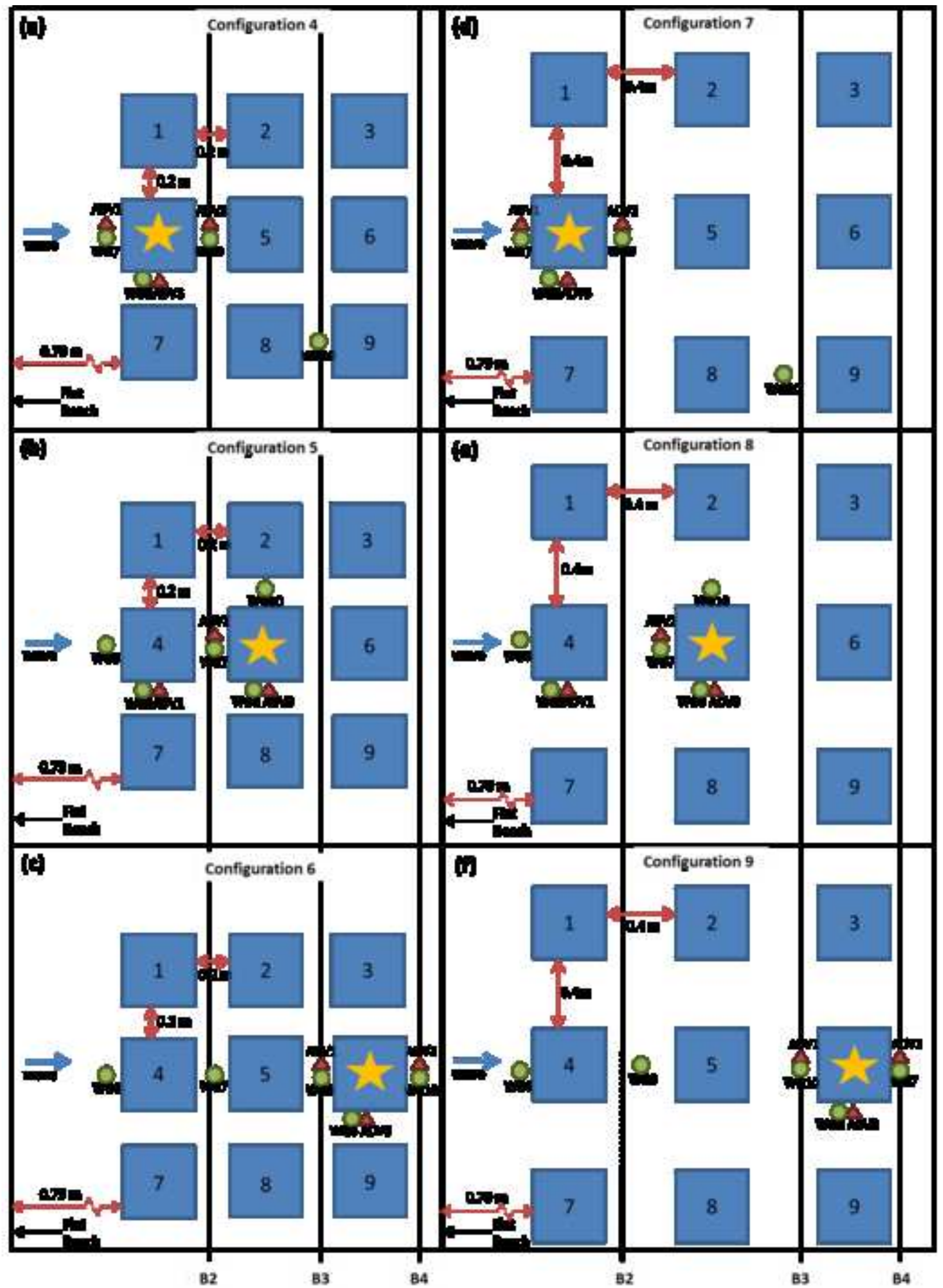



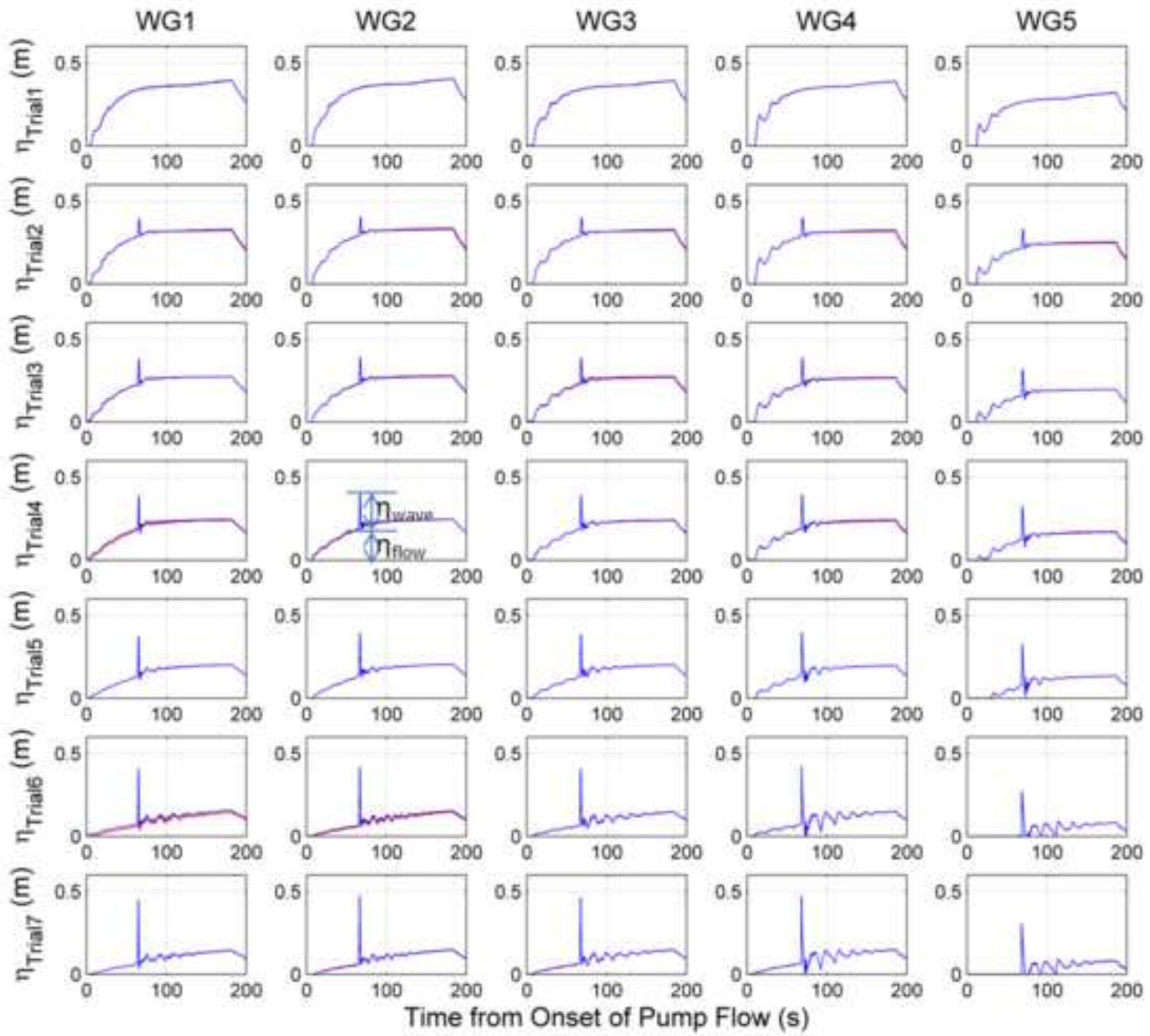

Time from Onset of Pump Flow (s) 

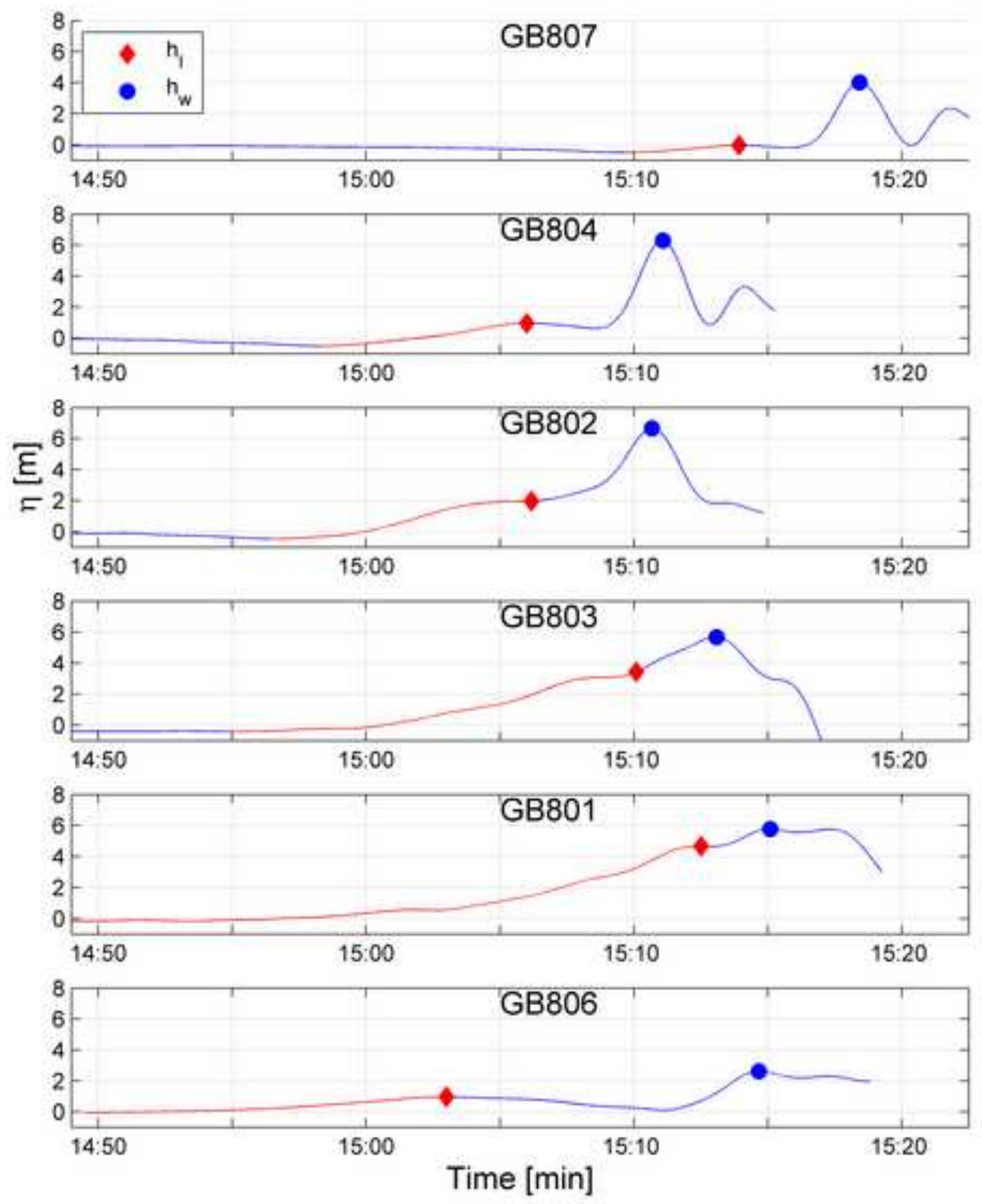


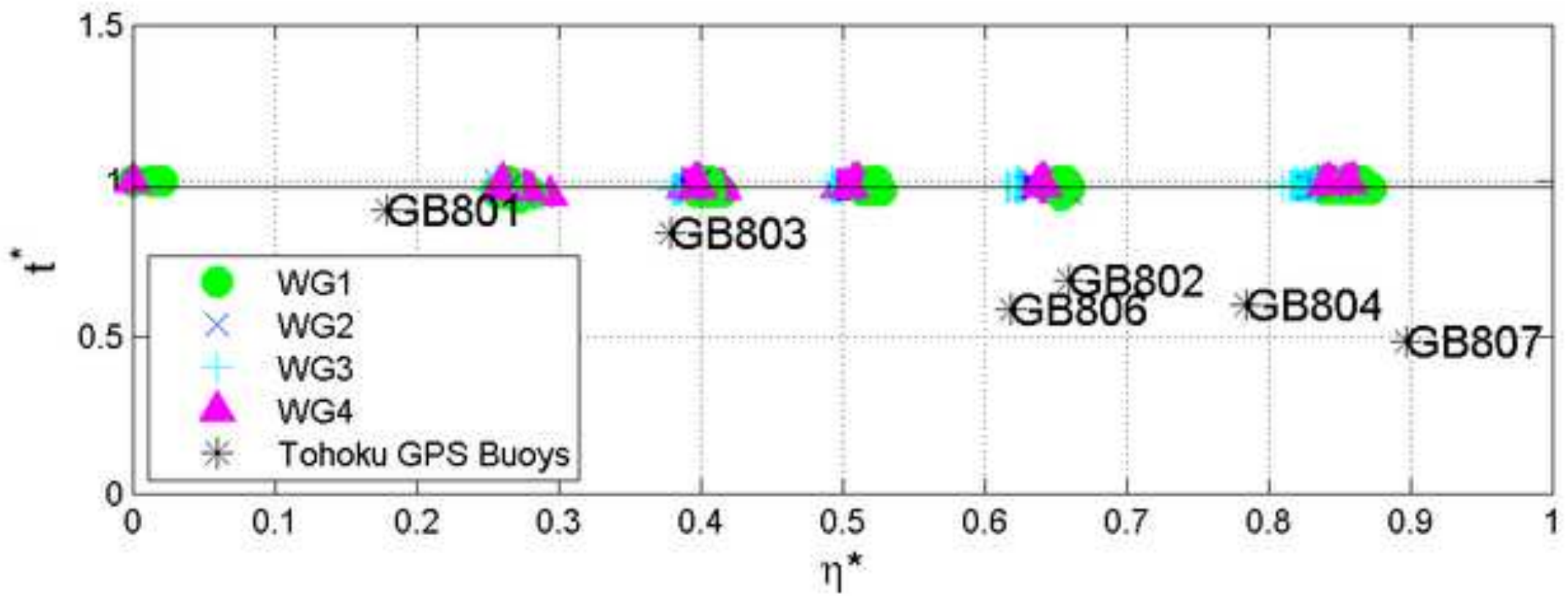


(a)

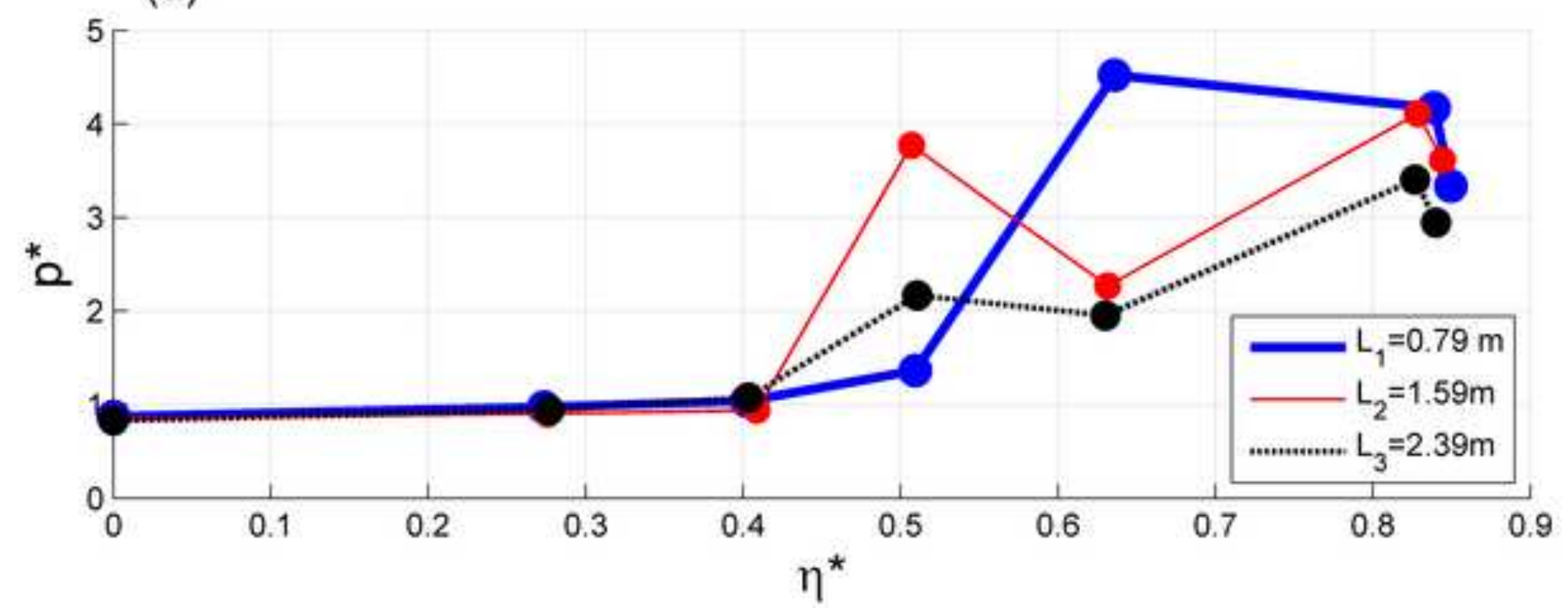

(b)

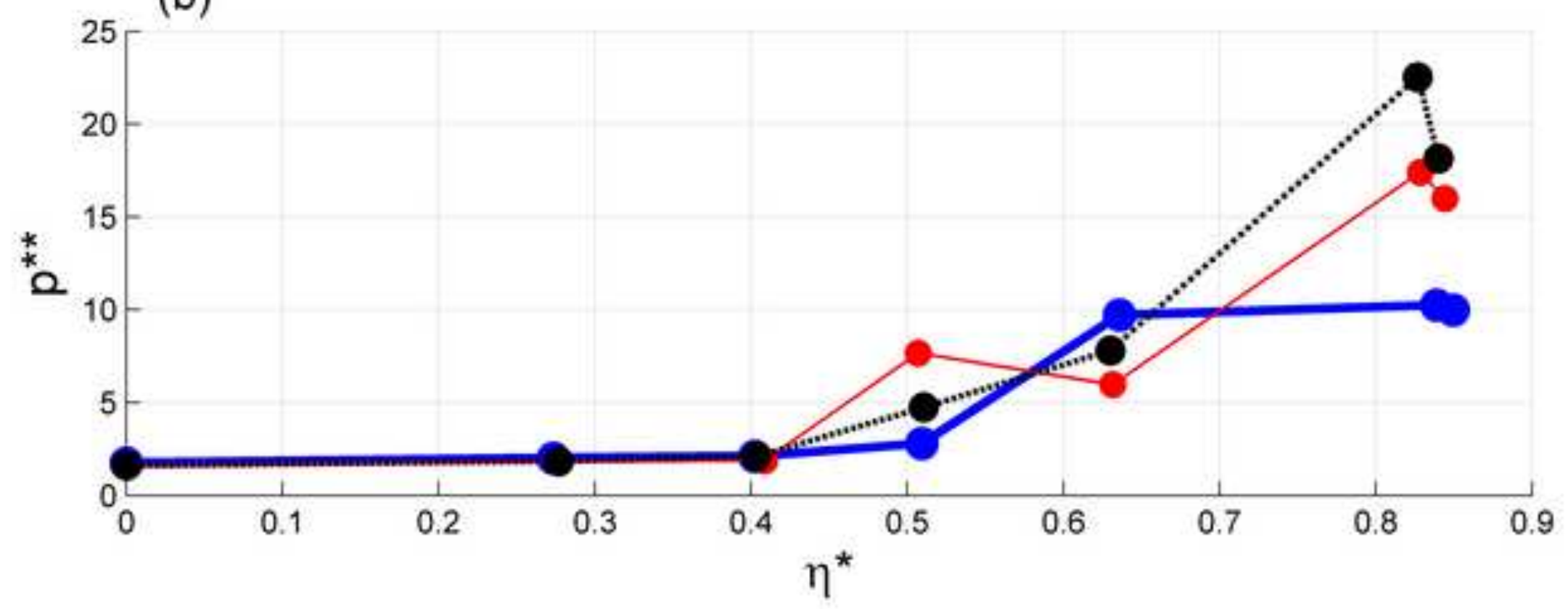




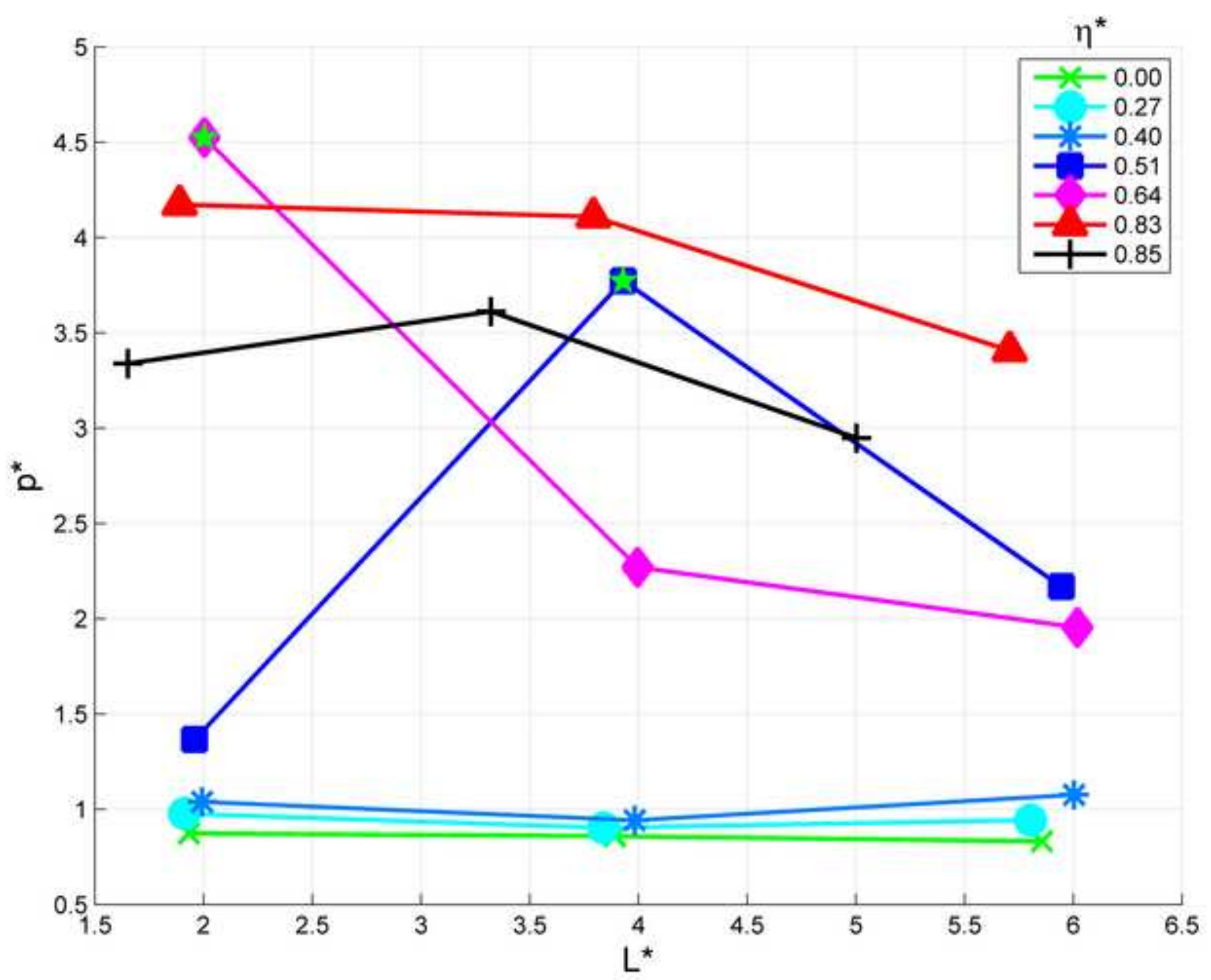



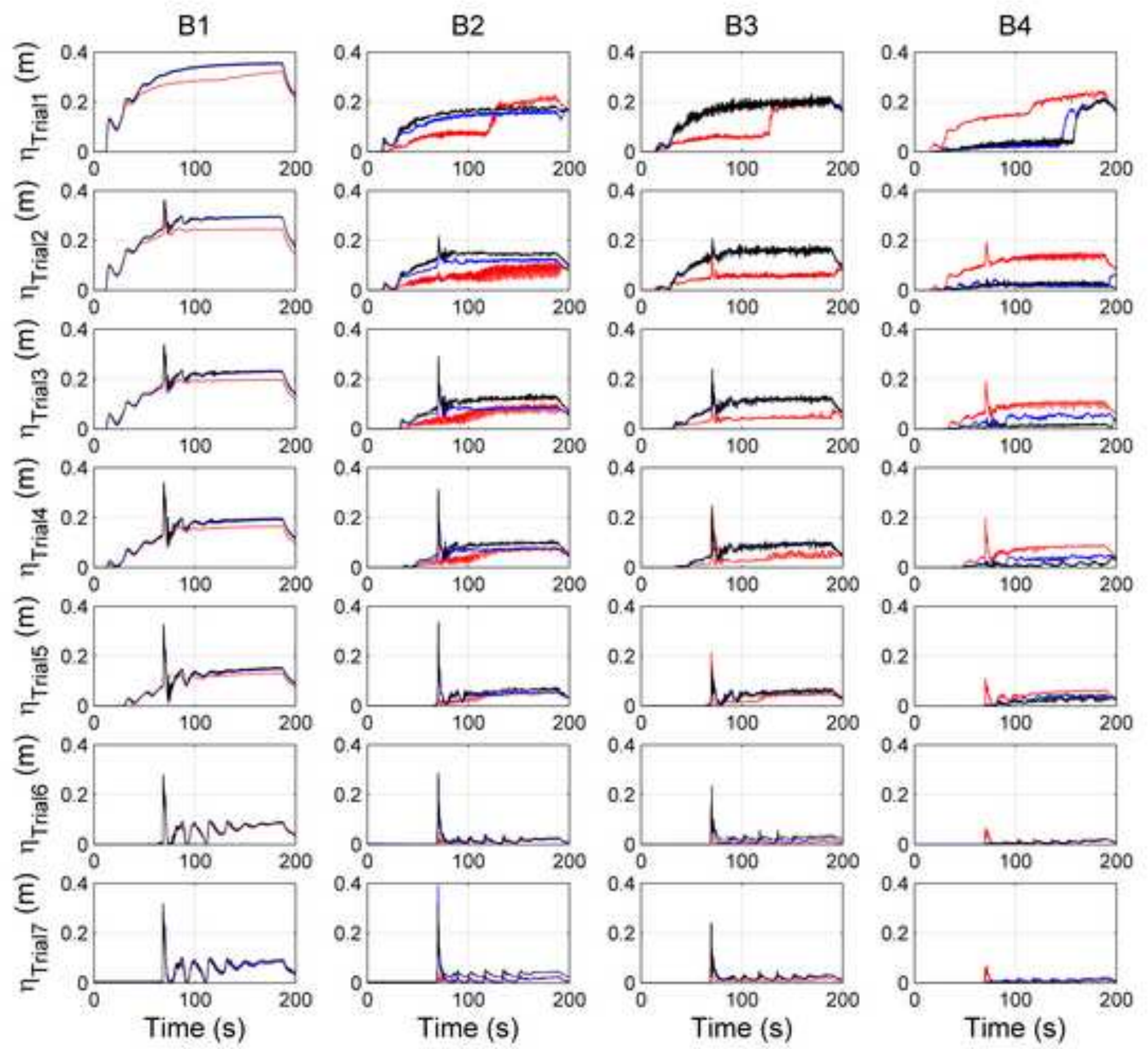

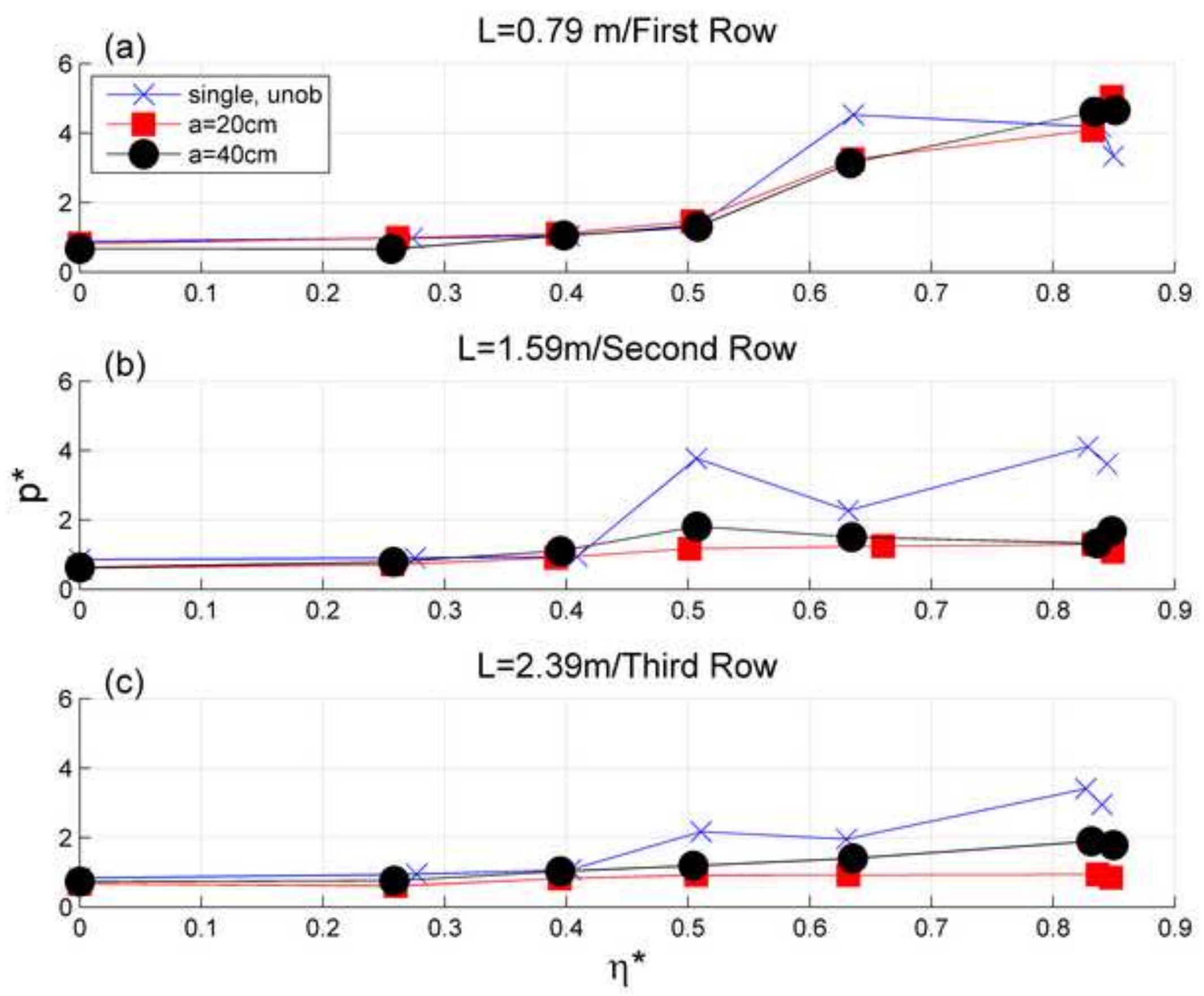